\title{
Trayectorias laborales de migrantes calificadas por razones de estudio
}

\author{
Rosa Emilia Bermúdez Rico*
}

En este artículo se analizan las trayectorias laborales de algunas profesionales universitarias colombianas que han realizado estudios de posgrado en México, y se abordan los principales patrones que caracterizan su inserción en el mercado laboral profesional, tanto en Colombia como en México. El propósito central es examinar la configuración de estas trayectorias laborales en relación a la experiencia de la movilidad por razones de estudio, tanto en la etapa previa a la migración internacional como en su etapa posterior, al permanecer en el país de destino o retornar al de origen. En este contexto se analiza el lugar que ocupa y el sentido que adquiere la movilidad internacional por razones de estudio en la trayectoria laboral y de vida de las mujeres profesionales universitarias. El análisis que se presenta constituye un estudio de caso de carácter exploratorio, fundamentado en un diseño de investigación cualitativa, bajo la perspectiva teórica y metodológica del curso de vida. Para ello se recabó información longitudinal y retrospectiva a partir de entrevistas a profundidad realizadas directamente a las mujeres migrantes, que posibilitaron la reconstrucción de sus biografias. El análisis muestra que este grupo de mujeres ha aplicado diversas estrategias, entre las que destacan los mecanismos de resistencia y de adaptación como alternativas para enfrentar el mercado laboral profesional tanto en Colombia como en México. A partir de este análisis se identificaron cuatro tipos de trayectorias laborales en las que se articula la permanencia en la sociedad de destino o el retorno al país de origen y se consideran dos áreas de conocimiento.

Palabras clave: migración internacional calificada, trayectorias laborales, mercado laboral profesional, movilidad sur-sur y género.

Fecha de recepción: 15 de agosto de 2012.

Fecha de aceptación: 7 de junio de 2013.

\section{Career Paths of Skilled Migrants for the Purpose of Study}

This article analyzes the career paths of a number of Columbian university women who have pursued graduate studies in Mexico and explores the main patterns of their insertion in the professional labor market in both Colombia and Mexico. The focus is to examine the way these career paths have been shaped by the experience of mobility for the purpose of study during both the stage prior to international migration and the subsequent period, whether they remained in the country of destination or returned to

* Profesora investigadora del Departamento de Ciencias Sociales de la Universidad del Valle, Cali, Colombia. Correo electrónico: <rosa.bermudez@correounivalle.edu.co >. 
their country of origin. Within this context, the author analyzes the place occupied and the meaning acquired by international mobility for the purpose of study in the career paths of university women. The analysis constitutes an exploratory case study based on a qualitative research design, using the theoretical and methodological perspective of the life course. Longitudinal and retrospective information was compiled on the basis of in-depth interviews with migrant women, making it possible to reconstruct their biographies. The analysis shows that this group of women has used various strategies, including resistance and adaptation as alternative means of coping with the professional labor market in Colombia and Mexico. This analysis was used to identify four types of career paths involving a combination of decisions as to whether remain in the host society or return to the country of origin, on the basis of two areas of knowledge.

Key words: skilled international migration, career paths, professional labor market, south-south mobility and gender.

\section{Introducción}

Un rasgo distintivo de la movilidad internacional de la población en las sociedades contemporáneas lo constituye el dinamismo que ha alcanzado la migración calificada. Este incremento en la movilidad de recursos humanos altamente calificados ha estado acompañado de la emergencia de diversos y heterogéneos patrones y constituye un renovado flujo internacional. En este contexto, la movilidad internacional por razones de estudio se ha configurado en un flujo específico de la migración calificada y ha alcanzado una magnitud sorprendente en el contexto de la sociedad globalizada. ${ }^{1}$ La movilidad por razones de estudio puede ser considerada, en la actualidad, como una estrategia de cualificación que adopta la población con estudios superiores para enfrentar las cambiantes condiciones laborales. ${ }^{2}$

${ }^{1}$ El número de estudiantes en educación profesional, que se encontraba realizando estudios en el extranjero en el año 2001 se estimó en 2 millones de personas; en tanto que para el año 2005 se había incrementado hasta alcanzar 2.7 millones de personas, y para 2010 se registró que la movilidad internacional de estudiantes de este nivel fue gestionada por más de 3.5 millones de personas en el mundo (UNESCO, 2004, 2007 y 2012).

${ }^{2} \mathrm{El}$ concepto de estrategia alude a un mecanismo de respuesta, que puede ser de adaptación o de resistencia con respecto a una situación cambiante que enfrenta el sujeto individual o colectivo, donde se pone en juego la capacidad de acción de los actores sociales considerando las condiciones estructurales en que se inscriben. Una amplia revisión sobre la discusión teórica que este concepto ha tenido en las ciencias sociales y en particular sobre su conceptualización y uso en los estudios de población se encuentra en Villasmil, 1998. 
En este artículo se examinan algunas de las características que ha adquirido este fenómeno en la actualidad en el contexto de América Latina y, de manera particular, se estudia el flujo de mujeres profesionales colombianas que se movilizan a México a realizar estudios de posgrado. Dos procesos de orden estructural constituyen la antesala que abre un marco de posibilidad a la migración calificada femenina: en primer lugar, el incremento constante de la participación de las mujeres en el sistema educativo y el mayor nivel de profesionalización que han logrado; en segundo lugar, la cada vez mayor y sostenida participación en el mercado laboral de las mujeres altamente escolarizadas. Ambos procesos han representado cambios sustanciales en la posición de las mujeres en la sociedad colombiana y, de esta forma, son factores estructurales altamente influyentes en la cada vez más importante participación femenina en la migración calificada colombiana (Docquier, Lowell y Marfouk, 2009; Lozano y Gandini, 2011; Bermúdez, 2012).

En este contexto se reflexiona en torno al lugar y el significado que adquiere este tipo de movilidad en las trayectorias de vida de algunas mujeres migrantes que, tras obtener un título de licenciatura en su país de origen, se movilizan a nivel internacional para realizar estudios de posgrado. Con ese propósito se analizan los procesos de inserción laboral y las estrategias que adoptan para concurrir al mercado de trabajo; se examina el sentido de estas experiencias contemporáneas en el mundo del trabajo y su significado para este grupo de mujeres. Con estos fines se analizaron las trayectorias laborales de 24 mujeres profesionales migrantes por razones de estudio que se movilizaron a México a realizar estudios de posgrado, en su mayoría en condición de becarias del gobierno mexicano, y que fueron entrevistadas por la autora durante el año 2010.

Los criterios para seleccionar a las mujeres entrevistadas fueron: mujeres colombianas con titulación de licenciatura, en ciencias sociales o ciencias naturales, obtenida en su país de origen, que hubieran migrado a México a realizar estudios de maestría o doctorado entre 1991 y 2007 y que, tras haber terminado algún nivel de estudios de posgrado, se encontraran participando en el mercado laboral de la Ciudad de México o hubieran retornado a Colombia y se hubieran integrado en el mercado laboral de Bogotá. ${ }^{3}$ Tales criterios se estable-

${ }^{3}$ Las entrevistas que se realizaron consistieron en extensas conversaciones acerca de sus trayectorias de vida enfatizando en sus recorridos educativos y laborales, sus vidas familiares y sus relaciones de pareja tanto en Colombia como en México y, en ese contexto, de su experiencia migratoria y su permanencia en la sociedad de destino o su retorno a la sociedad de origen. 
cieron en correspondencia con el perfil altamente calificado de este flujo migratorio y en busca de facilitar el análisis comparativo entre ellas en cuanto a que respondieran a una misma razón de movilidad y a que sus referentes de temporalidad fueran equivalentes, de tal forma que las condiciones estructurales y de tiempo histórico social que están en el trasfondo de esta movilidad fueran compartidas por el grupo.

La delimitación temporal establecida para realizar el análisis de las trayectorias laborales, entre 1991-2010, corresponde con la configuración de los nuevos escenarios laborales y, de esta manera, con la experiencia vivida por las primeras generaciones de egresados/as de las universidades que se incorporaron al mercado laboral profesional en el contexto de las reformas estructurales de la década de los noventa. Este periodo, igualmente, corresponde a la dinamización del flujo migratorio de colombianos/as a México desde mediados de los años noventa (Bermúdez, 2012).

Para contactar a las mujeres que se habían movilizado por razones de estudio y cumplían con los criterios planteados para ser entrevistadas se acudió a su búsqueda en distintas fuentes de información: listados de estudiantes egresados/as de los más importantes posgrados ofrecidos por las distintas instituciones de educación superior en el Distrito Federal; hojas de vida de las investigadoras y docentes adscritas al Departamento Administrativo de Ciencia, Tecnología e Innovación de Colombia -Colciencias-; listados de profesoras de las más importantes universidades públicas y privadas en Bogotá, y redes de colombianos/as para obtener referencias personales de migrantes colombianas, tanto en México como en Colombia. Se contactó a las personas identificadas principalmente por medio de sus direcciones electrónicas tanto de tipo institucional como personal, se les presentaron los propósitos de la investigación y se les solicitó participar mediante una entrevista personal. Excepcionalmente se utilizó la estrategia de bola de nieve como referencia para llegar a otras candidatas a ser entrevistadas, pero en ningún caso se practicó más de una entrevista como referencia de un mismo contacto. El número de entrevistas se estableció con miras a disponer de suficiente información para realizar el análisis propuesto y llegar a un punto de saturación en la información recabada.

El artículo se estructura de la siguiente manera. En primer lugar se examina la importancia teórica y metodológica que ha adquirido el análisis de las trayectorias laborales en el contexto del capitalismo flexible. En segundo lugar se presentan las trayectorias laborales de las mujeres colombianas que han migrado por razones de estudio, 
comparando las que permanecen en México con las que retornaron a Colombia y diferenciándolas según el campo disciplinario de adscripción y la cohorte de titulación de licenciatura. Se examinan según las variables mencionadas, con el propósito de establecer una caracterización de estas trayectorias laborales y analizarlas en el contexto general de sus trayectorias de vida. En tercer lugar se presentan elementos de análisis en torno al lugar que ocupa y el significado que adquiere la movilidad internacional por razones de estudio en la trayectoria profesional de este grupo de mujeres y, para finalizar, se presentan algunas consideraciones de conjunto.

\section{Acerca de las trayectorias laborales}

El análisis de las trayectorias laborales de las colombianas profesionales migrantes por razones de estudio a México resulta valioso en la perspectiva de comprender las lógicas y los procesos que acompañan esta movilidad y el significado que adquiere para las mujeres migrantes esta estrategia de cualificación profesional en el marco de sus trayectorias de vida. Más aún, cuando se trata de un análisis que centra su atención en el flujo calificado de mujeres sur-sur, un flujo considerado no hegemónico y que incluye dos dimensiones poco estudiadas y hasta ahora casi ignoradas por completo en la literatura emergente en este campo: la movilidad internacional de mujeres calificadas y la movilidad de población calificada entre países latinoamericanos.

La migración internacional constituye un proceso complejo en el que el individuo se enfrenta a un conjunto de decisiones que debe tomar en distintos momentos de su trayectoria vital y en diversos escenarios, siempre sujeto a un marco de posibilidades definidas por las condiciones estructurales que ha enfrentado y que marcan su trayectoria de vida. En este marco general la migración calificada en condición de estudiante aparece como un evento de transición en la trayectoria laboral y de vida de hombres y mujeres y, por tanto, este flujo migratorio representa un proceso relevante por su carácter abierto en el que todo está por definirse: la inserción laboral posterior al proceso de cualificación educativa; las condiciones de retorno, y la opción de permanencia en el país receptor al cambiar de estatus ocupacional, entre otros.

El análisis realizado de las trayectorias laborales de este grupo de mujeres profesionistas se inscribe en los postulados generales de la 
orientación teórica y metodológica del curso de vida, perspectiva que se enfoca en el análisis de la participación de los individuos en distintos dominios institucionales -la familia, el trabajo, la escuela- a lo largo de su vida. De tal forma que el curso de vida establece una secuencia de eventos y roles sociales en relación con la edad, que están incrustados en la estructura social y en el cambio histórico (Elder, 2001). La pertinencia de este enfoque está en directa relación con el propósito central de comprender la manera en que "los eventos históricos y los cambios económicos, demográficos, sociales y culturales configuran las vidas individuales y los agregados poblacionales denominados cohortes o generaciones" (Blanco, 2011: 6).

Los conceptos centrales de la perspectiva del curso de vida son las trayectorias y las transiciones. Las trayectorias vitales establecen una perspectiva de largo plazo y ofrecen una visión dinámica del comportamiento de los individuos en un dominio o ámbito específico o en su interrelación. En tanto, las transiciones representan un cambio de estado, ofrecen una visión de corto plazo y siempre están contenidas en las trayectorias (Elder y Kirkpatrick, 2000). La perspectiva del curso de vida enfatiza los eventos que marcan cambios importantes en los dominios institucionales en los que un individuo participa, o subraya el entrelazamiento de diferentes eventos en los dominios analizados que configuran trayectorias individuales específicas (Solís, 2011).

La trayectoria refiere, por tanto, a una línea que se traza a lo largo de toda la vida a partir de un conjunto de eventos que se le presentan al sujeto de una manera particular, algunos se definen como transiciones, constituyendo cambios de estado, y otros, se definen como turning point, en tanto constituyen fuertes modificaciones que implican virajes en la dirección del curso de vida.

El análisis de las trayectorias laborales implica una reconstrucción de la carrera construida en las experiencias de empleo y de trabajo desarrollada por las personas, acudiendo a una mirada retrospectiva de la historia laboral, identificando los vínculos laborales a los que se ha tenido acceso en el marco de una serie de circunstancias diversas que han definido las posibilidades de ocupación y de empleo a lo largo de la vida. En este recorrido el sujeto ha estructurado un perfil ocupacional y ha configurado una identidad profesional que marca su experiencia laboral y estructura su experiencia vital.

Las trayectorias laborales están estrechamente relacionadas con las trayectorias educativas, dada la influencia directa que se ejerce entre estos dos ámbitos de la vida. En el caso de las mujeres, las trayec- 
torias laborales están igualmente asociadas y entrelazadas con la trayectoria familiar, especialmente con los eventos del ámbito reproductivo, tal como se ha reconocido en una vasta literatura que ha examinado las relaciones entre el trabajo femenino y la vida familiar (Suárez, 1992; García y Oliveira, 1998; García et al., 2000; Welti y Rodríguez, 2000; Blanco, 2001; Arriagada, 2002; Blanco y Pacheco, 2003; Pacheco y Blanco, 2008). De ahí la importancia de articular analíticamente estas trayectorias e identificar sus relaciones e implicaciones, así como de considerar las relaciones entre el trabajo extradoméstico, el lugar otorgado a la maternidad y el significado que tiene en la vida de las mujeres, según sus trayectorias, el nivel de escolaridad y de la clase social, entre otros factores (García y Oliveira, 1998; Pacheco y Blanco, 2008).

De igual forma, el análisis de la trayectoria laboral puede incluir la identificación de momentos de transición considerados de importancia significativa según el tipo de estudio a realizar (Jiménez, 2009). Considerar momentos de transición y turning point permite dar cuenta de trayectorias menos lineales y menos homogéneas, y es posible analizar los entrelazamientos o giros de redefinición que se presentan a lo largo del tiempo entre diferentes dominios, tal como se ha expuesto.

Las investigaciones sobre trayectorias laborales han adquirido una particular importancia en las últimas décadas en correspondencia con el reconocimiento de su mayor heterogeneidad y variabilidad actuales frente a la relativa linealidad que las caracterizó en el pasado (Tilly, 1998; Pérez y Mora, 2004; Bermúdez, 2007). Este cambio sustancial en las historias laborales contemporáneas corresponde a los cambios estructurales en el mundo del trabajo, de tal forma que la desregulación y la inestabilidad laboral que predominan en el mundo actual han cambiado la relación que se establece con el trabajo y han modificado las fronteras entre diversos ámbitos de la vida (Sennett, 2000).

Los cambios en el mundo laboral de las últimas décadas plantean, además, la necesidad de indagar en otras formas de construcción de significados distintos de los tradicionales, configurados alrededor de la idea generalizada de un trabajo estable; los sujetos laborales se presentan en una amplia diversidad generacional, genérica y étnica; desarrollan una enorme movilidad ocupacional y territorial, y acceden en una amplia diversidad de formas a trabajo asalariado, no asalariado, por cuenta propia, sin contrato, sin remuneración, entre otros que exigen ser analizados (Guadarrama, 2008). 
En el contexto del actual capitalismo, Fitoussi y Rosanvallon (1997) sostienen que nos encontramos en una nueva era de las desigualdades que se caracteriza por la superposición de dos fenómenos:

en primer lugar, se ampliaron las desigualdades a las que se podría calificar de "tradicionales" o estructurales, las que describen por ejemplo la jerarquía de ingresos entre categorías sociales (profesionales liberales, ejecutivos, dirigentes de empresas, empleados, obreros, etc.). Pero también se extendió su campo, lo que modificó en profundidad la percepción de las diferencias en la sociedad. Así, hicieron su aparición nuevas desigualdades, que proceden de la recalificación de diferencias dentro de categorías a las que antes se juzgaban homogéneas [...] Las nuevas desigualdades son ante todo "intracategoriales". Situaciones diferentes con respecto al desempleo, dentro de una misma categoría, pueden generar desigualdades considerables en términos de ingreso y patrimonio [Fitoussi y Rosanvallon, 1997: 73].

Con este planteamiento se sugiere que el cambio en el modelo económico ha acarreado el deterioro de las condiciones de trabajo y ha ampliado de manera significativa la brecha de desigualdad social, subrayándose que este proceso no sólo se presenta entre grupos sociales, también entre individuos que pertenecen a una misma categoría. Desde esta perspectiva analítica la sociedad resulta menos legible, ya que las desigualdades estructurales aparecen acompañadas por nuevas desigualdades de estatus indeterminado. Las desigualdades intracategoriales pueden volverse más importantes y tan persistentes como las intercategoriales. De ahí que su crecimiento contribuya a modificar la estructura misma del sistema y a debilitar su coherencia.

En la perspectiva de las nuevas desigualdades una dimensión que gana importancia es el seguimiento de las trayectorias efectivas de los individuos, dado que se considera que se presenta un cambio fundamental en la percepción que tiene cada individuo de la ubicación en cualquiera de los mundos de inseguridad e incertidumbre laboral posibles; percepción que se asume como un hecho aleatorio, mediado por la "suerte". Por tanto, "las trayectorias resultan no sólo de la calidad de las dotes iniciales, sino de la relación de los individuos con la coyuntura" (Fitoussi y Rosanvallon, 1997: 88).

Así, en una trayectoria de vida cada individuo puede experimentar cambios sustanciales, procesos de movilidad ascendente y descendente en el corto y mediano plazos; periodos de éxito y fracaso laboral aleatorios, situaciones de empleo con seguridad y desempleo forzado 
por periodos extendidos. Todas estas situaciones se presentan como hechos dados y supeditados a las circunstancias del momento, sin que el individuo pueda tener explicaciones más allá de las condiciones contingentes que enfrenta.

Por tanto, el giro analítico y metodológico que enfatiza la importancia de examinar las trayectorias individuales se sustenta en el hecho de que, en contraste con los estudios clásicos sobre movilidad social intergeneracional, en las circunstancias actuales del capitalismo flexible los procesos de cambio -de movilidad social, niveles de ingresos, calificación apropiada, desempeño profesional, entre otros-se pueden observar en un mismo sujeto a lo largo de su vida. La incertidumbre e inestabilidad propias del capitalismo actual, plantean la aleatoriedad como una característica dinámica y permanente en la vida de los sujetos. Así, se puede afirmar que la experiencia vivida por el sujeto capta los dos niveles de desigualdades: tanto las estructurales -persistentes en el planteamiento de Charles Tilly (1998)-, como las nuevas desigualdades, planteadas por Fitoussi y Rosanvallon (1997); de ahí la importancia y validez de los estudios que abordan las trayectorias de vida como nuevo escenario analítico.

Adicionalmente, en los nuevos contextos laborales la exposición al riesgo se presenta a nivel individual, es decir, en lo fundamental es un asunto que enfrenta y resuelve el individuo. La idea de grupo -de clase social- que actúa por intereses compartidos y "negocia" con una institucionalidad que media entre intereses de clase social o de grupo queda desdibujada, poniéndose en juego las condiciones y las dotes individuales y, de esta forma, la representación cotidiana de la desigualdad adquiere significados diversos. La experiencia de vida de cada individuo se vuelve así relevante, y el énfasis analítico se centra en la heterogeneidad que se presenta en los subgrupos; en el interior de una misma categoría analítica las diferencias que cuentan son aquellas que transcurren en los individuos que pertenecen a un mismo grupo pero que desarrollan movilidades y negociaciones diferenciadas, que establecen sentimientos y afinidades que cuestionan el patrón de desigualdad social predominante y, al mismo tiempo, lo trascienden. 


\section{Las trayectorias laborales de las migrantes por razones de estudio}

A partir de los inicios de la década de los noventa del siglo pasado en Colombia, como en el resto de los países de América Latina, se llevaron a cabo profundas reformas constitucionales y reestructuraciones económicas y productivas que introdujeron significativas transformaciones en los fundamentos de la sociedad salarial (De la Garza, 2007; Prieto, 2008; Zapata, 1998; Urrea, 1999; Pérez y Mora, 2004). En tal contexto y en forma correlativa con estos procesos se configuró un nuevo escenario laboral, caracterizado por una mayor flexibilidad en el trabajo, tanto en los contratos como en las jornadas laborales, y una mayor inestabilidad en el empleo e inseguridad social (De la Garza, 2011; García, 2011). A su vez estas políticas laborales han favorecido una mayor movilidad de la fuerza de trabajo, introduciendo importantes cambios económicos, sociales y culturales. Este profundo proceso de cambio social y de crisis de la sociedad del empleo se presenta de manera diversa conforme a dimensiones estratégicas en la estructuración social: la clase, el sexo, el nivel educativo alcanzado, la edad y la etnia, entre las más importantes. Es en este contexto de transformación de los mercados laborales en el que se inscribe y adquiere su mayor importancia el análisis de las trayectorias laborales de las mujeres profesionales migrantes colombianas que se movilizaron a México para realizar estudios de posgrado. Este grupo de mujeres forma parte de las recientes generaciones de profesionales que se han insertado en el mercado de trabajo en el marco de este nuevo régimen laboral.

Las trayectorias laborales que se analizan a continuación tratan de mujeres que, dadas las características de sus hogares de origen, forman parte de las clases medias en Colombia. Un rasgo sobresaliente en tal sentido es el alto capital escolar que presenta la mayoría de sus padres, y en muchos casos también sus madres, al haberse titulado en la universidad como profesionistas y, en ocasiones, haber cursado estudios de posgrado. Esta posición de clase facilita el apoyo brindado a sus hijas para que realicen estudios en la universidad e incluso para que cursen estudios de posgrado. En estos hogares la educación constituye un valor central en la estructuración de la vida, y su proyecto educativo está asociado con una aspiración de clase social para conservar el lugar que se hereda en la estructura social. Este aspecto gana importancia, dado que en las últimas décadas la relación directa entre un mayor nivel educativo y un mejor empleo, que prevaleció en el capita- 
lismo, ha sido redefinida para establecerse como una relación incierta y cada vez más ambivalente, en correspondencia con la redefinición más general del régimen laboral que se mencionó en el apartado anterior. Adicionalmente a los aspectos de caracterización social de este grupo de mujeres, es importante subrayar que se trata de un flujo migratorio de una alta selectividad, si se considera que sólo el $7 \%$ de las mujeres colombianas había accedido a la educación profesional en el año 2005 (DANE, 2005). ${ }^{4}$ Esta selectividad es mucho más significativa si se considera que el grupo de mujeres entrevistadas no sólo culminaron con éxito sus estudios profesionales en Colombia, sino que también realizaron estudios de posgrado en el extranjero, en este caso en México. ${ }^{5}$

La reconstrucción y el análisis de las trayectorias laborales se realiza a partir de cinco momentos clave en el recorrido laboral del grupo de mujeres entrevistadas: el primer empleo tras la titulación en la universidad en el campo específico del área de conocimiento; el empleo que se tenía en Colombia antes de la movilidad internacional; el empleo que se tuvo mientras se realizaron los estudios de posgrado en México; el empleo posterior a la realización del posgrado, y el empleo en el momento de la entrevista en México, para quienes permanecían en este país, o en Colombia para quienes habían retornado. En esta secuencia de empleos o de ocupaciones se parte de la consideración de que el punto de quiebre o inflexión -turning point- está dado por la movilidad internacional, señalando un cambio en el antes y en el después de la realización de los estudios de posgrado en cuanto al trabajo que se desempeña y a las condiciones laborales a las que se accede, aspecto que analizaremos de manera central en este apartado (cuadros 1 y 2 ).

El análisis realizado de las trayectorias laborales de las mujeres migrantes por razones de estudio ha permitido establecer cuatro tipos de recorridos o carreras que presentan dinámicas comunes y diferenciadas, tanto en rasgos de orden estructural como de orden subjetivo,

${ }^{4}$ Para estimar el nivel educativo de la población se considera la población de 3 años y más.

${ }^{5}$ Sólo para tener una referencia de alta selectividad de este flujo migratorio, en el año 2005 los estudiantes colombianos que migraron fuera del país, según las estadísticas de la UNESCO, se estimaron en 19 903, que representan el 12.7\% de los estudiantes movilizados en este nivel en América Latina para este año, lo que se traduce en una tasa de movilidad hacia el extranjero de los estudiantes colombianos de 1.7. La tasa de movilidad de estudiantes de un país determinado hacia el extranjero es el número que estudia en el extranjero como porcentaje del total de estudiantes matriculados en educación terciaria en dicho país (UNESCO, 2007: 199). 


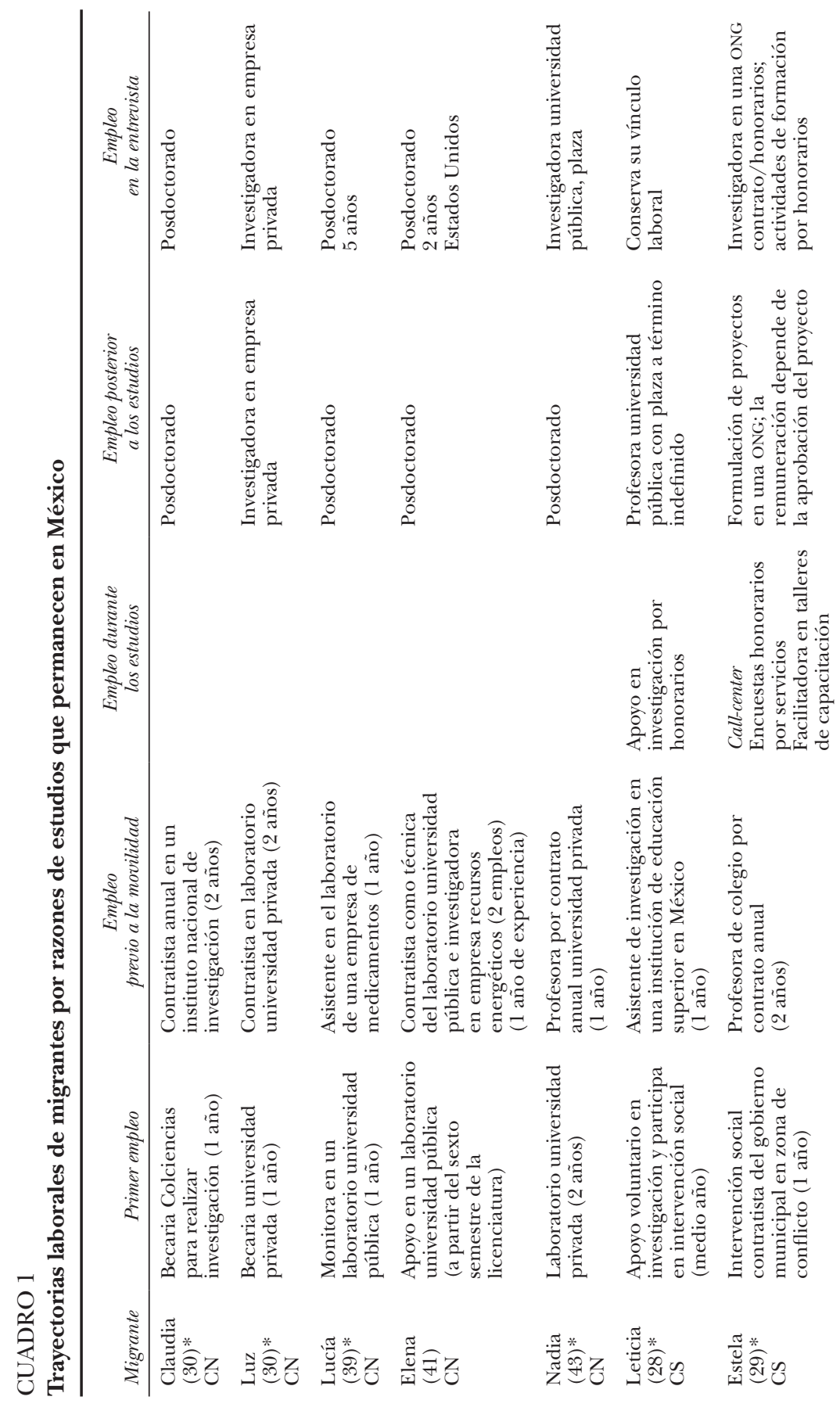




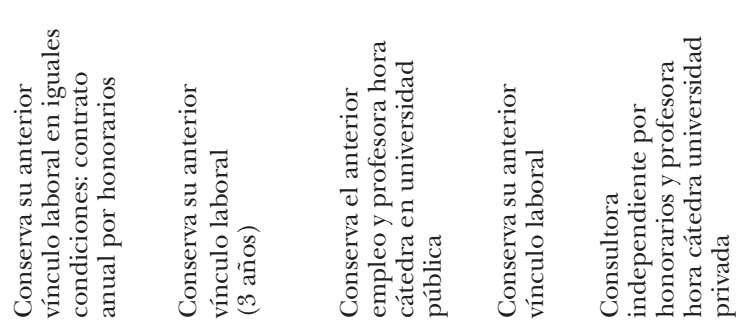

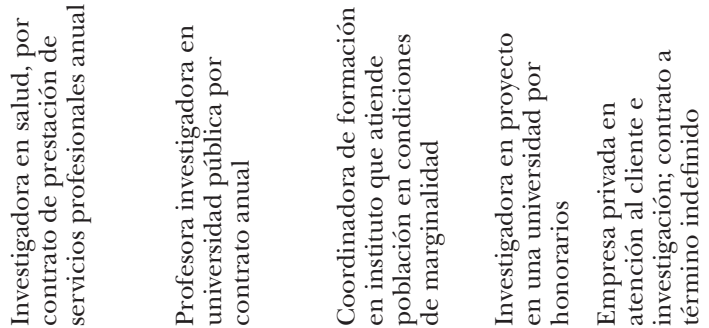

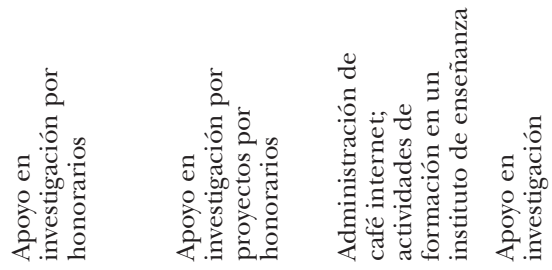

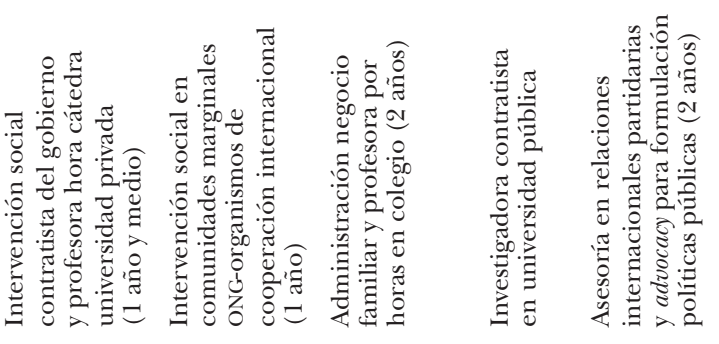

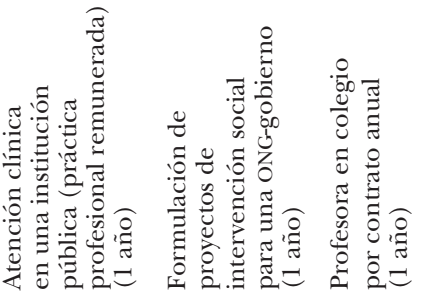

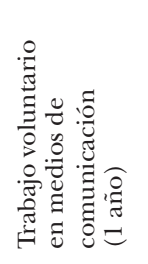

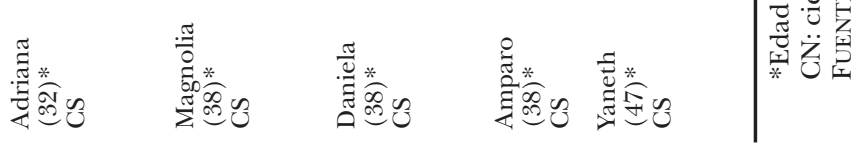




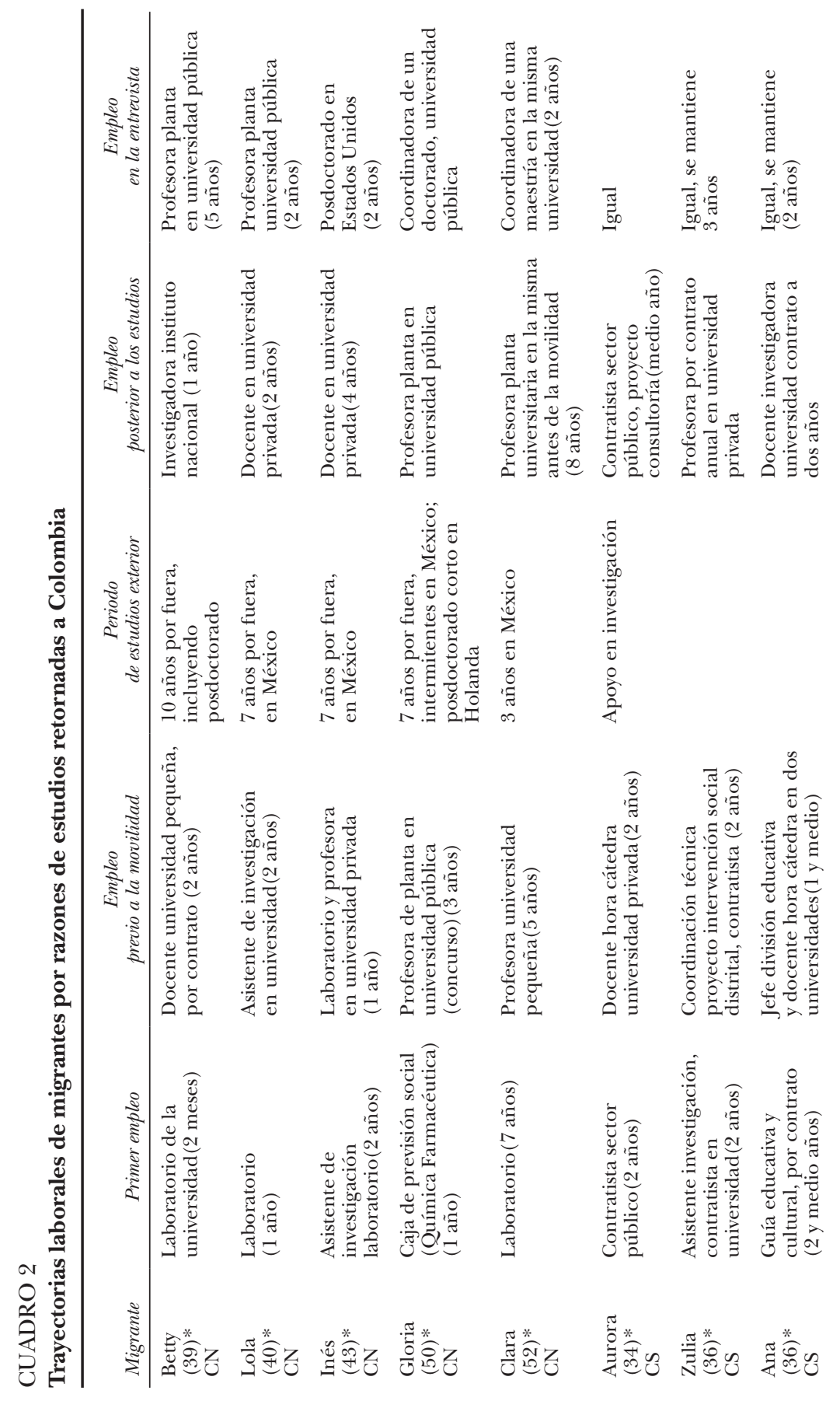



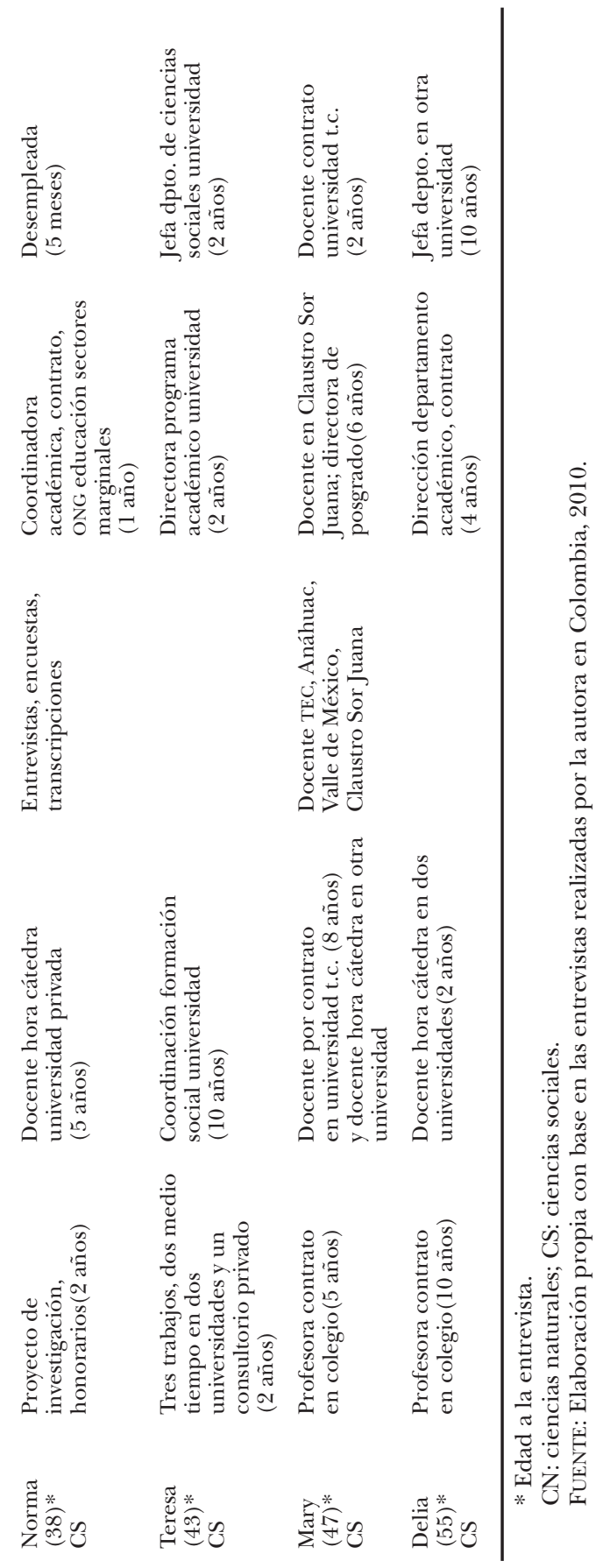
constituyéndose cada uno en un tipo de trayectoria laboral. Las categorías definidas corresponden a las migrantes que permanecen en México así como a las que han retornado a Colombia, tanto de ciencias naturales como de ciencias sociales. Se ha considerado válida esta agrupación para el análisis propuesto, ya que permite examinar las diferencias en los mercados de trabajo por área de conocimiento y de acuerdo con los dos contextos: el país de destino y el de origen. Asimismo, conforme a esta clasificación examinamos las variaciones y rupturas que caracterizan a cada uno estos subgrupos. Para cada tipo presentamos un diagrama síntesis de la trayectoria de vida de las migrantes, señalando los eventos centrales y la información de referencia: año de nacimiento, edad a la migración, año de titulación de licenciatura, edad a la entrevista, periodos de vínculo laboral, años en la formación de posgrado, vínculos establecidos en la condición de posdoctorado, año en que se ha tenido hijos/hijas (diagramas 1, $2,3$ y 4$)$.

\section{Una vida forjándose como investigadoras científicas}

Las profesionales en el campo de las ciencias naturales que permanecen en México constituyen el grupo representativo de esta categoría. Sus trayectorias laborales se caracterizan por tener un periodo de vínculo laboral muy corto en relación con el mayor número de años dedicados a la formación académica a lo largo de su vida. Su proyección profesional está centrada en adquirir un alto estatus de investigadoras, que les otorgue la autoridad y el reconocimiento suficiente para consolidar una línea de investigación propia y contar con la suficiente experiencia para lograr el financiamiento de sus propios proyectos de investigación y los de un equipo de trabajo bajo su dirección. Sus edades en el momento de la entrevista fluctuaban entre los 30 y los 43 años y se ubicaban en una etapa de consolidación media en su ciclo de vida (cuadro 1 y diagrama 1).

En el inicio de sus trayectorias laborales desarrollaron actividades de apoyo en investigación en la academia, principalmente de carácter voluntario o, si recibían alguna remuneración era más de carácter simbólico que real. La vinculación a este tipo de actividades se presenta frecuentemente antes de concluir la licenciatura; al titularse se continúa en estos espacios ocupando un cargo de mayor responsabilidad. Así se puede pasar de monitora a técnica encargada del laboratorio, 


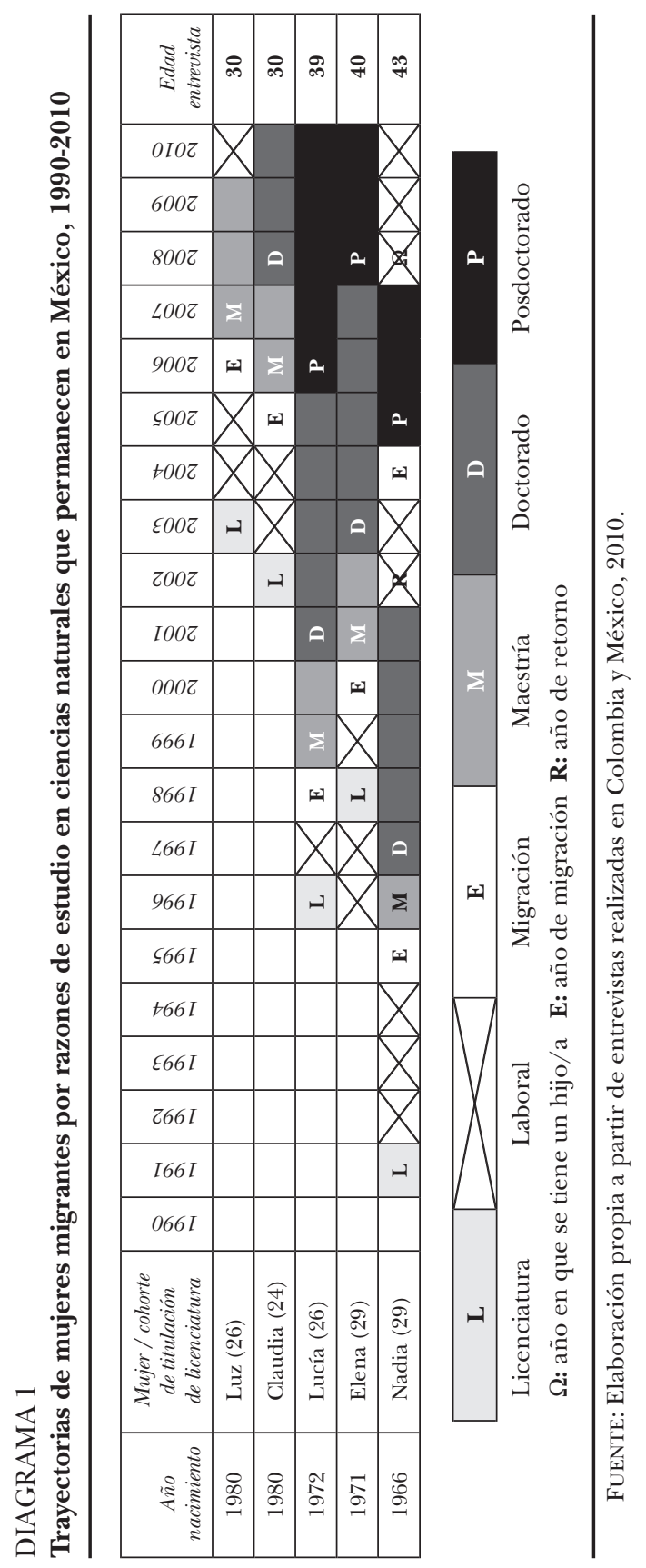




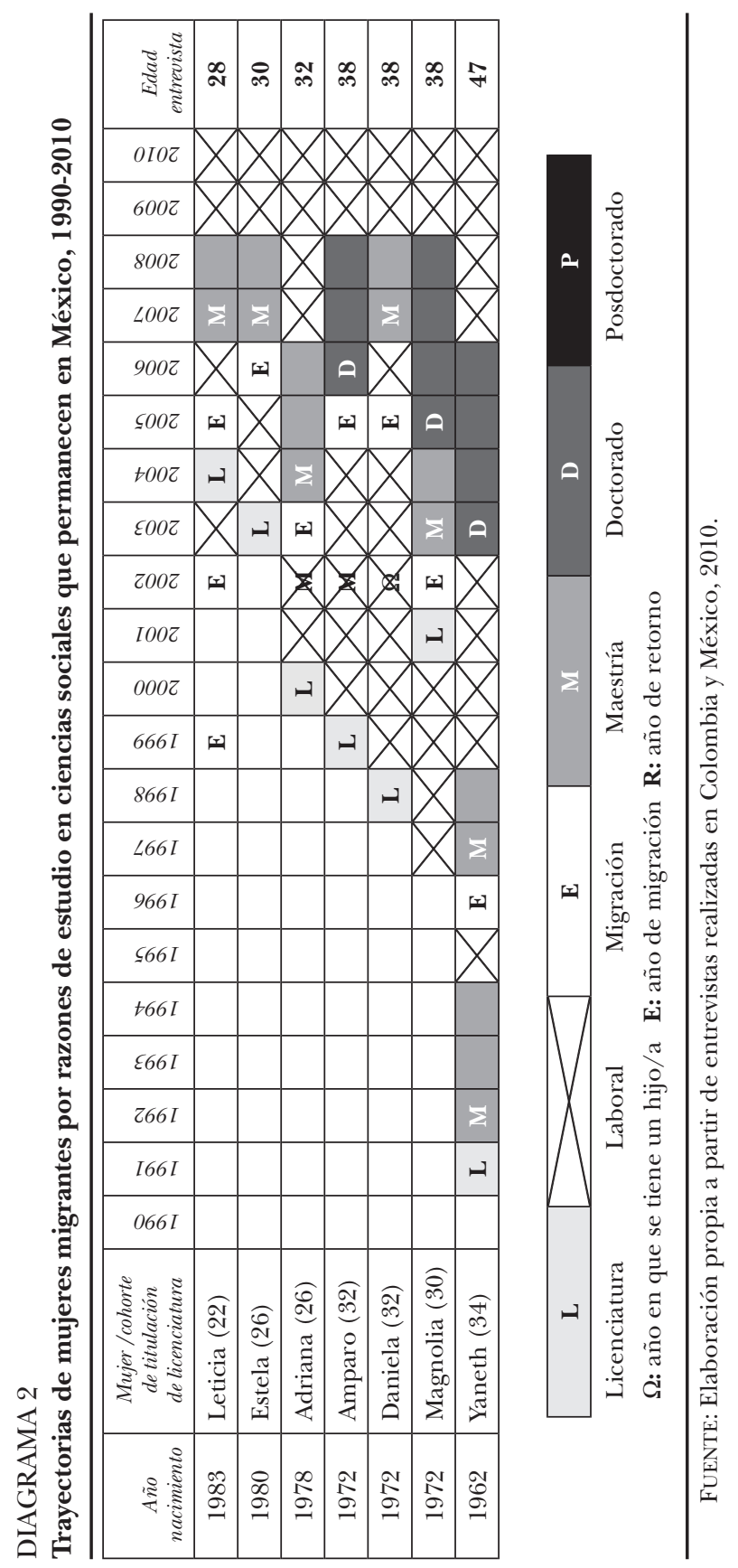




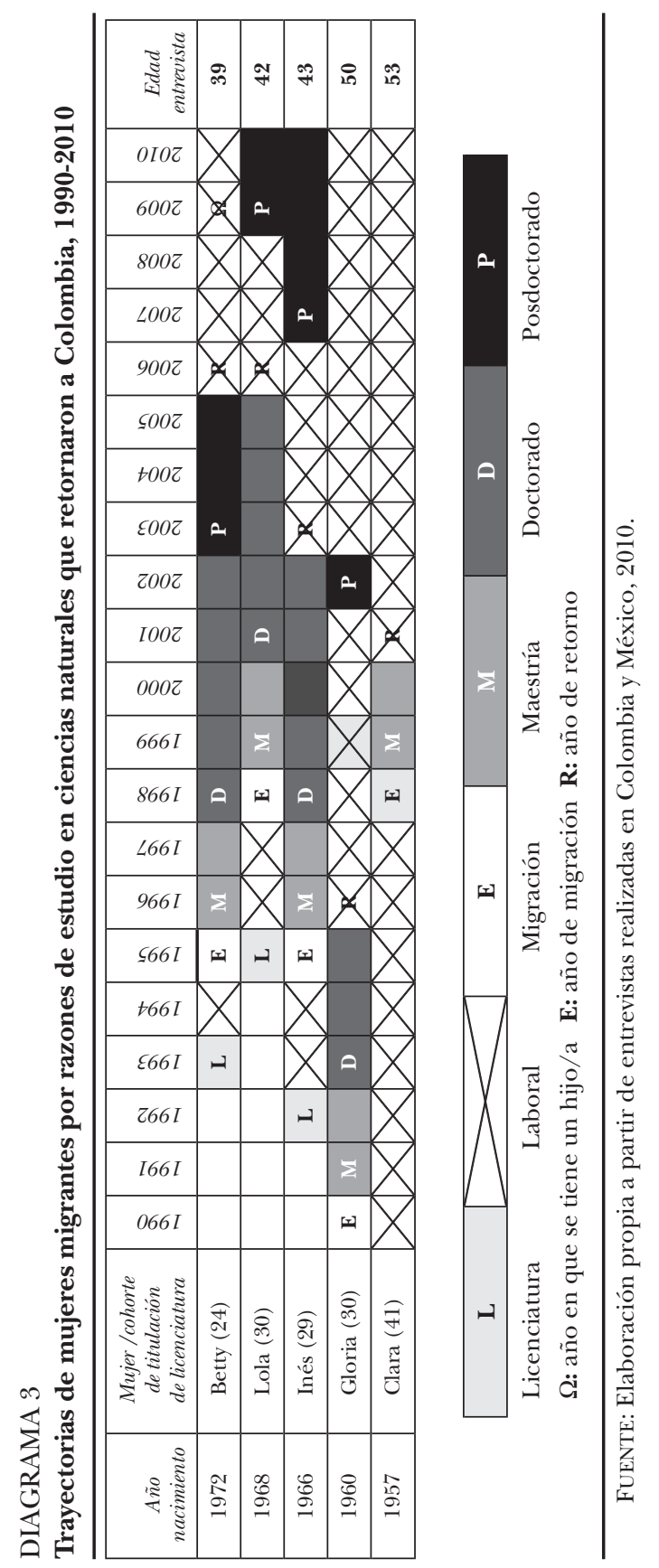




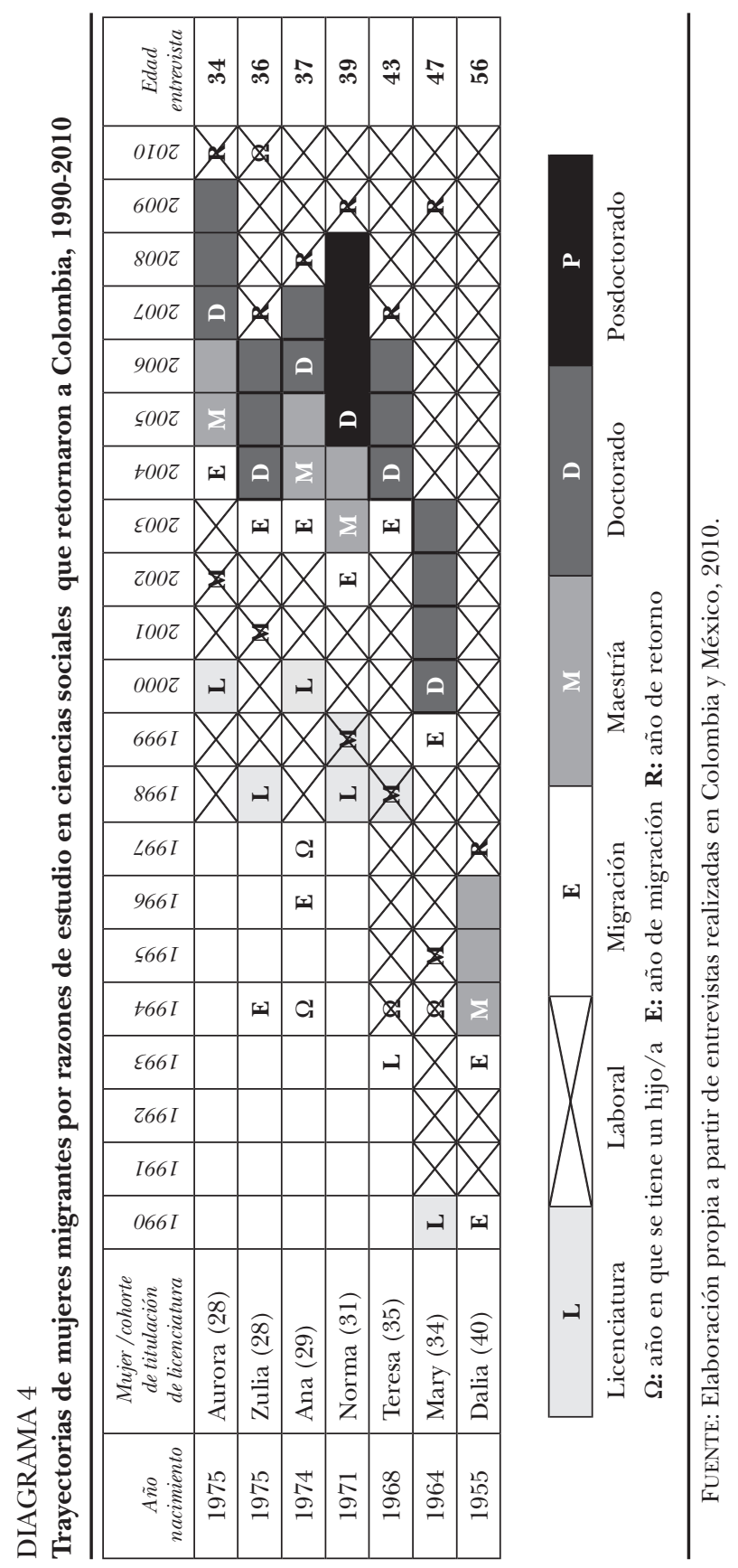


en el caso de Elena, ${ }^{6}$ o de becaria de Colciencias a tener un contrato anual por prestación de servicios profesionales, en el caso de Claudia (cuadro 1). ${ }^{7}$

Este primer empleo no les provee ingresos suficientes para su sostenimiento y no les ofrece una situación de independencia económica de sus familias de origen, sino que dados los bajos ingresos, esta opción implica la permanencia en la casa de sus progenitores. Tampoco representa ningún tipo de seguridad social en salud o pensiones.

El empleo, antes de la movilidad internacional, aparece como una continuidad del primer vínculo de trabajo, con leves modificaciones en los términos contractuales. La experiencia laboral que acumularon antes de la movilidad no fue superior a tres años, y el primer empleo y el empleo antes de la movilidad fueron los dos únicos vínculos laborales que tuvieron. Este vínculo se conserva, a pesar de las condiciones de desventaja laboral, porque el trabajo en una institución de investigación y de carácter académico no sólo constituye un espacio de aprendizaje y entrenamiento en el campo profesional, sino que también es una referencia fundamental para postularse como candidata en las instituciones educativas internacionales y continuar así los estudios de posgrado.

Tras este corto vínculo laboral prosigue el periodo de formación en maestría y doctorado, realizados de manera continua, y que requiere en todos los casos al menos siete años de permanencia formal en las instituciones educativas en México (diagrama 1). La formación de maestría y doctorado se asume, por parte de este grupo de mujeres, como un trabajo más, tal como lo expresa Claudia en este fragmento de entrevista: "a mis estudios yo les llamo trabajo porque estoy de 9 de la mañana a 9 de la noche en el laboratorio; tú trabajas en la investigación que estás haciendo, ése es mi trabajo". ${ }^{8}$ De hecho, la interacción que se desarrolla en el laboratorio se expresa en forma de vínculos laborales, tales como denominar al investigador principal como "mi jefe ", mantener una relación de jerarquía no solo académica, también respecto al manejo del tiempo, a la presentación de resultados de investigación, y a la retribución económica, entre otras.

Tras este periodo de formación aparece inmediatamente la realización del posdoctorado, planteándose como un nuevo escenario de formación especializada; se asume como una estrategia laboral y se

\footnotetext{
${ }^{6}$ Entrevista a Elena, México, julio de 2010.

${ }^{7}$ Entrevista a Claudia, México, julio de 2010.

${ }^{8}$ Entrevista a Claudia, México, julio de 2010.
} 
presenta como una experiencia de trabajo. El vínculo posdoctoral es variable, entre 1 a 5 años, siendo común para este grupo de mujeres la realización de varios posdoctorados, incluso combinando su formación tanto en México como en Estados Unidos, en algunos casos.

Las dificultades para lograr un vínculo laboral como investigadora titular en una institución de educación superior están asociadas con la permanencia en los posdoctorados, que les permite adelantar una investigación, pertenecer a un equipo acreditado con financiación, con posibilidades de publicar y con perspectivas de lograr hallazgos importantes en el campo, producto del trabajo colectivo en el laboratorio.

En esta trayectoria parece imprescindible contar con la mayor formación posible para enfrentar el competitivo escenario laboral, considerando la expectativa que se tiene de ocupar un lugar de distinción dentro del mismo. El tiempo de formación, por esa razón, se prolonga y se extiende ilimitadamente. Esta consideración subyace en la decisión de permanecer en el estatus de becaria de posdoctorado y desarrollar periodos tan prolongados de formación y trabajo de manera continua en el nivel de posgrado, entre 7 y 12 años, y en la condición de migrante residente en México. Aunque esta estrategia incluye en algunas ocasiones la participación de convenios con la empresa privada para financiar investigaciones, esto no implica una relación salarial como tal, sino que se acude a otras formas de vínculo que redefinen la relación laboral o la mantienen en una condición de subsidio o beca para el desarrollo de una investigación.

La trayectoria laboral tiende a tornarse difusa y hay una redefinición subjetiva del trabajo tal como ha sido señalado. En estas condiciones no se accede a ningún tipo de seguridad social ni se ha logrado un patrimonio a partir de ingresos laborales. No obstante, las mujeres de este subgrupo expresan que ése es el costo que tiene mantenerse en este campo y poder hacer investigación, y lo asumen con tranquilidad y convicción, con perseverancia y sin afanes; convencidas de que ésa es la exigencia del camino de la investigación científica que se han planteado recorrer en sus vidas.

La migración internacional aparece en dichas trayectorias laborales como la oportunidad de consolidar la participación en el mundo de la investigación científica; constituye un peldaño hacia el logro de su proyecto de llegar a ser una investigadora o científica reconocida en un campo de especialización y de alcanzar una dimensión global en la esfera del conocimiento y la interacción de los circuitos y redes en el área. De tal forma, la movilidad internacional para es- 
tudiar constituye un rito de paso imprescindible para lograr su aspiración por el camino señalado. El siguiente fragmento de la entrevista a Claudia ilustra al respecto:

Para alcanzar el nivel que necesito, si quiero hacer investigación en serio, tengo que invertir más tiempo; terminar este posdoctorado y tratar de hacer uno en Estados Unidos. Lo necesito para apostarle a un puesto de investigadora, para algún día tener mis propios proyectos, estudiantes, ser jefa. Para mí el posdoctorado es una oportunidad laboral. Mi éxito fue hacer el doctorado; en el posdoctorado sigues aprendiendo, pero ya te reconocen como investigadora, porque ya sabes hacer mucho más. Desde que yo empecé en el mundo de la investigación, yo dije, quiero ser investigadora, éste es el camino, es mi trabajo. Ésa es mi aspiración profesional. Es cumplir una meta [...] Con uno o con dos posdoctorados más bien la idea es buscar trabajo por fuera de Colombia; si buscas un posdoctorado también estás buscando una oportunidad laboral mejor. ${ }^{9}$

Al observar las trayectorias de vida del grupo de mujeres que corresponden a este primer tipo de trayectoria laboral en las mujeres especializadas en ciencias naturales que permanecen en México se distinguen algunos aspectos característicos. Se resalta el importante número de años dedicados a la formación de posgrado, en contraste con los pocos años de vínculos laborales formales. Asimismo, destaca el hecho de que ninguna de ellas tuviera hijos/as antes de realizar sus estudios de licenciatura en Colombia ni de posgrado en México. Nadia tuvo un hijo después de que finalizó un posdoctorado y en una edad avanzada, casi al término del periodo reproductivo de su ciclo de vida. En tanto Elena y Lucía, que han construido relaciones de pareja estables, no tienen hijos; a este tipo de hogares se les conoce como hogares con el "nido vacío"10 (diagrama 1). En ambos casos manifestaron que la maternidad no había sido una opción para ellas y que dada su edad actual era muy poco probable que la asumieran posteriormente; resaltaron así mismo que el tipo de actividad que desarrollaban les resultaba más difícil considerar dicha opción en sus vidas. De igual forma Luz y Claudia, las más jóvenes, expresaron expectativas muy acotadas res-

${ }^{9}$ Entrevista a Claudia, México, junio de 2011.

${ }^{10}$ Arriagada (2002) ha presentado una clasificación de nuevos tipos de hogares en América Latina que consideran el tipo de vínculo establecido entre las parejas, su corresidencia o cohabitación de la pareja, el tener hijos o no, y la edad de la mujer, entre otras características. A las parejas sin hijos en donde la mujer tiene 40 años o más se le denomina de nido vacío. 
pecto a la relación de pareja posible, y mucho más inciertas y limitadas respecto a su rol materno en el futuro. En esta forma se advierte que la exigente trayectoria educativa termina condicionando las opciones reproductivas en este subgrupo de mujeres. En el marco de una migración extendida en el tiempo, este condicionamiento aparece como un importante factor de viabilidad y eficacia en la estrategia de cualificación.

\section{La inserción laboral como transición}

En el subgrupo constituido por las mujeres migrantes profesionales adscritas a las ciencias sociales que permanecen en México se observó que en sus trayectorias laborales es muy corto el periodo inicial de vínculo laboral y se suspende para ingresar a un periodo de formación de posgrado igualmente corto, para tras éste reincorporarse nuevamente al mercado laboral. Esta alternancia entre periodos de estudio y de trabajo remunerado caracteriza las trayectorias laborales de estas profesionales migrantes. Su edad se encuentra entre 28 y 47 años, ubicándose en una etapa de consolidación media en su ciclo de vida (cuadro 1 y diagrama 2).

La experiencia laboral profesional antes de la movilidad es inferior a los tres años y el primer empleo y el empleo previo a la movilidad fueron los dos únicos vínculos laborales que tuvieron. Magnolia, la excepción, presenta una amplia experiencia laboral desarrollada de manera simultánea a la realización de sus estudios de licenciatura, la cual en su caso fue la única alternativa para financiar su formación en este nivel (cuadro 1).

Las mujeres de esta categoría se movilizaron a nivel internacional para realizar estudios de maestría y se insertaron de manera formal -con permiso de trabajo- al mercado laboral en México al finalizar sus estudios de posgrado. Su proyección en el mediano plazo es continuar su proceso de formación realizando estudios de doctorado, ya sea en México o en Estados Unidos, lo que está estrechamente relacionado con su decisión de permanecer en México. Este patrón es válido también para quienes realizan su doctorado en México y se vinculan laboralmente con la proyección de realizar un posdoctorado, en el mediano plazo, en otro país.

El inicio de estas trayectorias laborales es diverso en cuanto al tipo de funciones, instituciones y vínculos laborales establecidos. Algunas 
de ellas desarrollaron un trabajo voluntario sin remuneración monetaria en actividades de investigación dentro de instituciones académicas o campos especializados, mediante el cual lograron ingresar al medio y ganar experiencia en los ámbitos laborales de su interés. Otras mujeres iniciaron su trayectoria laboral en programas de intervención social, colaborando directamente con el gobierno municipal o en proyectos ejecutados por organizaciones no gubernamentales. En estos casos el vínculo laboral es un contrato por prestación de servicios a término definido. También, aunque es menos común, inician su trayectoria laboral como docentes de colegios de secundaria, mediante un contrato cuya duración es la del ciclo escolar (cuadro 1).

En los empleos que ejercieron antes de la movilidad se identifica una línea de continuidad con respecto al primer empleo en cuanto al tipo de vinculación laboral, la duración y el tipo de actividades que desarrollaron; con ligeras alternancias, la mayoría se mantiene en el universo descrito. En general, en estos trabajos se sugiere que desempeñaban funciones de mayor alcance y responsabilidad; sólo en el caso de Adriana hay una incorporación al ámbito académico propiamente dicho como docente por hora cátedra en una universidad privada ${ }^{11} \mathrm{y}$ en el caso de Leticia en el ámbito de la investigación mediante su vínculo con una institución mexicana. ${ }^{12}$ En estos casos se advierte un giro cualitativo hacia actividades académicas. La movilidad internacional por razones de estudio ocurre en este momento y con los relativamente limitados antecedentes laborales descritos.

Durante la realización de sus estudios de maestría, la mayoría de este grupo de mujeres tuvo la oportunidad de establecer cortas y eventuales experiencias laborales, casi siempre de carácter informal -sin permiso de trabajo y sin ningún tipo de vínculo contractual- con pago por honorarios. Tales experiencias de trabajo casi siempre implicaron el desarrollo de actividades dentro de su campo de conocimiento, aunque con menor exigencia en cuanto a la calificación requerida; casi todas se relacionaban con la realización de trabajo de campo, recolección o procesamiento de información como apoyo a investigaciones, horas de docencia y apoyo en la redacción de informes de investigación (cuadro 1). Dichas experiencias de participación en actividades remuneradas en el ámbito de la formación profesional constituyeron antecedentes importantes para su aproximación al mercado laboral, para acrecentar su confianza frente a la calidad del trabajo que desempeña-

${ }^{11}$ Entrevista a Adriana, México, abril de 2010.

${ }^{12}$ Entrevista a Leticia, México, abril de 2010. 
ban, para explorar posibles vínculos, y en fin, para acercarse al desempeño profesional y al mercado de trabajo calificado en las condiciones de la sociedad de destino.

Terminado el ciclo de estudios de maestría, se incorporaron de manera formal al mercado laboral en instituciones de diverso tipo: gubernamentales, organizaciones civiles, entidades de investigación internacional, empresas privadas, e instituciones de educación superior. La vinculación se hizo de manera inmediata, con contrato de trabajo a término definido y pago por honorarios, en ocupaciones directamente relacionadas con su ámbito de formación profesional y de especialización, desarrollando actividades de docencia -en distintos niveles-e investigación. La mayoría se encuentra en condiciones laborales relativamente inciertas de temporalidad; asumen estos trabajos como una alternativa de ingresos y de ejercicio profesional aceptable mientras definen o materializan su itinerario en el mediano plazo. La experiencia de Yaneth ilustra este proceso. Al terminar su maestría entró a trabajar en una empresa privada donde permaneció varios años desempeñando una labor que constituyó un ámbito de formación importante para ella. Varios años después decidió realizar un doctorado, de manera simultánea con su trabajo, sin beca, para darse la oportunidad de continuar laborando, siempre de manera independiente.

Nunca tuve que buscar trabajo, siempre me llegó. Siempre me informé de todo, buscaba opciones. Trabajaba tres meses seguidos y luego me dedicaba a la tesis. No podía dejar ni una cosa ni la otra. Seguí trabajando por mi cuenta, me titulé y he seguido trabajando por mi cuenta. He tenido suerte, nunca he sentido miedo. Aquí no tengo familia que me apoye y tenía que encontrar opciones de trabajo, no podía quedarme sin trabajo. Ya conociendo como es la cultura mexicana, sobre todo tienes que tener amigos, no puedes integrarte a la sociedad mexicana sin amigos, sin tener vínculos. Es importante tu capacidad, pero aquí se valoran mucho tus relaciones. Nunca estuve buscando, siempre me llegó, con los amigos. Yo me titulé en el 2006, fueron siete años haciendo el doctorado en esas circunstancias. Ahora hago proyectos de consultoría y de capacitación; también doy una clase en una universidad. No siempre trabajando de manera independiente tienes el permiso para trabajar, pero siempre encontré quien me apoyara. ${ }^{13}$

Por su parte, Leticia, quien es la única que presenta una vinculación a término indefinido con la asignación de una plaza como profesora

${ }^{13}$ Entrevista a Yaneth, México, mayo de 2010. 
e investigadora en una universidad, reconoce que sus condiciones laborales son excepcionales, pero aun así su horizonte de mediano plazo es incierto. $\mathrm{Al}$ respecto comenta:

Pues creo que en el trabajo que tengo aquí, tengo la libertad de hacer muchas cosas, porque puedo hacer investigación y producir en muchos sentidos, ¿no?, pero tampoco creo que me vaya a quedar aquí en México, o sea lo veo como una opción para aprender, producir, pero sí quisiera volver a Colombia después de aprovechar lo que tengo aquí un rato [...] yo creo que las condiciones que tengo hoy aquí no las podría volver a tener, ni siquiera aquí mismo [risas] [...] Yo creo que si volviera a Colombia podría tener condiciones laborales para trabajar en proyectos de investigación, sí, pero lograr una plaza en una universidad pública eso sólo lo podría lograr como en diez años por lo menos ¿no? Entonces, también lo pienso, cómo decir, bueno, pues, más bien, voy a aprovechar esto y volver con más armas para defenderme allá, ¿sabes? ése es el punto, que si vuelvo a Colombia tengo que volverme muy fuerte $[\ldots]$ es tan exigente volver a Colombia que mejor me fortalezco aquí que tengo los medios y sé cómo hacerlo. Porque eso me ha pasado aquí en los cinco años que he estado, que siempre ha habido una opción, eso me parece ¡uf! ${ }^{14}$

Estas trayectorias laborales muestran un horizonte aún por definirse, un proceso inconcluso o sin consolidación, una búsqueda en el horizonte abierto que aún presenta múltiples dilemas por resolver en el mediano plazo. La movilidad internacional por razones de estudio representó un salto cualitativo en la proyección profesional, y la permanencia en México les ha permitido mantenerse activas en términos laborales, aunque en la mayoría de los casos no resulta suficiente para acceder a la estabilidad laboral deseada. México sigue siendo un escenario con oportunidades educativas y de trabajo y la inserción laboral es una alternativa de espera y de adaptación, algo que se permiten con la proyección de aprovechar estas oportunidades en el mediano plazo; también constituye un mecanismo de resistencia para no regresar a Colombia. Por tanto, para este subgrupo de mujeres migrantes, en el contraste entre el aquí y el allá la balanza sigue inclinada hacia la sociedad de destino.

En este grupo de mujeres la trayectoria laboral antes de la migración fue muy corta e inestable; la movilidad internacional para realizar estudios de posgrado constituyó un importante punto de inflexión en su formación y experiencia de vida. En este contexto, la inserción la-

${ }^{14}$ Entrevista a Leticia, México, mayo de 2011. 
boral en México es mucho más probable que el retorno a Colombia. Para ellas el paso por las instituciones educativas mexicanas representa un excedente que les otorga la oportunidad de incorporarse laboralmente; en varias ocasiones su sobresaliente desempeño académico y el respaldo de alta calidad de las instituciones donde realizaron sus posgrados les facilitan en gran medida su posterior inserción laboral en condiciones favorables.

En este subgrupo de mujeres se identifican otros aspectos de la vida que han sido postergados y que aún están indefinidos. Por un lado, aunque permanecen en México no es clara su determinación de estabilizarse en este país; por el contrario, la opción de regresar a Colombia o movilizarse a otro país se plantea explícitamente como una opción que consideran en el horizonte.

Por otro lado, la mayoría de estas mujeres declaró que las relaciones afectivas de pareja que han sostenido mientras han estado en México han sido transitorias, ya que como no se plantean un proyecto a largo plazo las circunscriben a su estancia en este país. Manifiestan que ante la posibilidad de formalizar las relaciones afectivas que han sostenido en México, han optado por agotarlas antes que consolidarlas, en tanto prefieren mantenerse en condiciones de tomar decisiones con mayor libertad porque asumen que están en la búsqueda de alternativas y no quieren "ataduras" ni dependencias de nadie. En este mismo contexto resulta interesante resaltar que ninguna de las mujeres que integran este subgrupo haya tenido hijos/hijas en su permanencia en México, durante o después de la realización de los estudios de posgrado (diagrama 2). De tal forma, la alternancia entre las exigencias en la trayectoria educativa y las transiciones de los vínculos laborales aparecen como condicionantes para establecer o proyectar las relaciones de pareja y para asumir opciones reproductivas.

\section{La fortuna de la estabilidad laboral: ipero hay que picar piedra!}

Las mujeres profesionales de las ciencias naturales que han retornado a Colombia se ubican en esta categoría. Sus trayectorias laborales se caracterizan por haber tenido vínculos con instituciones de diverso tipo, donde desempeñaron funciones de investigación y docencia antes de la movilidad internacional. Posteriormente tuvieron un periodo de formación de posgrado relativamente extenso -entre 7 y 10 
años- y luego una reincorporación laboral para desempeñarse como docentes e investigadoras en universidades de alta calidad, en donde han logrado estabilidad laboral. En lo sustancial, este recorrido y sus resultados son válidos tanto para las mujeres de cohortes recientes como para las de cohortes anteriores. Sus edades fluctúan entre 39 y 52 años, ubicándose en una etapa media y avanzada del ciclo de vida (cuadro 2 y diagrama 3 ).

La experiencia laboral profesional acumulada, previa a la movilidad por razones de estudio, es corta, entre 3 y 4 años, y con muy poca movilidad laboral. Sólo Clara tuvo una experiencia de más de 10 años. Todas ellas se movilizaron en el ámbito internacional para realizar estudios de maestría, y la mayoría continuó con sus estudios de doctorado de manera inmediata, con excepción de Clara, quien tan pronto terminó la maestría retornó a Colombia (cuadro 2 y diagrama 3).

$\mathrm{Al}$ terminar sus estudios de doctorado algunas regresaron a Colombia y otras partieron rumbo a Estados Unidos o Canadá a realizar investigaciones en algunas universidades, mediante vínculos posdoctorales. Las que regresaron a Colombia trabajaron como docentes en una universidad -pública o privada- y pocos años después emigraron nuevamente a otro país para realizar sus estudios de posdoctorado. Una vez concluido este nuevo ciclo formativo retornaron a Colombia. En medio de estas idas y vueltas se estructura un ciclo de trabajoformación-trabajo centrado en lograr una plaza como docente e investigadora en su campo de especialización dentro de una universidad.

Las migrantes que retornan a Colombia a reincorporarse a las universidades que apoyaron su movilidad para realizar estudios de posgrado, como es el caso de Gloria y Clara, quienes pertenecen a las primeras cohortes, retomaron su cargo de profesora investigadora y en los años siguientes fueron promovidas a la coordinación de posgrados en sus respectivas instituciones.

Para las mujeres pertenecientes a las cohortes más recientes, su situación, en varios aspectos, era mejor en el exterior. Con relación a sus estancias posdoctorales, los ingresos en Colombia, en este campo del conocimiento y para el nivel de calificación que alcanzaron, constituyen un factor de desventaja. La experiencia de Betty ilustra esta situación: su salario actual como docente de planta en una de las mejores universidades públicas en Colombia sólo representa $70 \%$ de lo que percibía en el posdoctorado en Estados Unidos. Sus publicaciones en revistas internacionales han disminuido en comparación con las posibilidades que tuvo en el extranjero, situación asociada con 
la lentitud para acceder al financiamiento, con la baja tecnología disponible en el país y con las limitadas conexiones institucionales para dar a conocer los artículos y responder a los dictámenes. La ausencia de respaldos institucionales reconocidos a nivel internacional hace más difícil este proceso. Los siguientes fragmentos de la entrevista ilustran al respecto:

aquí hay dos cosas que no lo dejan a uno avanzar y es la docencia y la falta de dinero [...] La investigación, por supuesto me fascina, pero no hay mucho tiempo; yo ahorita estoy en periodo de vacaciones pero estoy trabajando. ¡Claro! Porque no me puedo dar el lujo de tomarme las vacaciones, y no las aplazo porque después vienen esos líos de que le toca a uno irse obligatoriamente en medio de la investigación y del experimento que no puede dejar de observar día a día.

[...] Yo, allá estaba en el laboratorio todo el día, pipeteando, sacando, cultivando células, haciendo de todo, y aquí [...] rara vez me ves en el laboratorio; aquí no es lo mismo. En términos de investigación, realmente significa mucho, porque es menos productividad, cuando uno tiene la gente que trabaje o cuando uno trabaja, pues rinde más [...] pero aquí como hay tanta docencia, preparar una clase es un montón de tiempo, ése es el tiempo que le restas a la investigación. Regresar es como un golpazo, porque finalmente estabas mejor allá en términos de ingresos, de todo, bueno, uno de ingresos económicos, dos de productividad, porque estaba publicando casi que un artículo por año más o menos... y llegas aquí y pum, ni plata, ni productividad académica, pues esas dos cosas son muy duras. ${ }^{15}$

Este grupo de profesionales de las ciencias naturales que retornaron a Colombia han alcanzado una incorporación laboral en el campo de especialización en el que se formaron y han alcanzado un desempeño profesional académico importante, adquiriendo con el tiempo condiciones de estabilidad laboral y forjando en la actualidad dinámicas de punta en el ámbito de la docencia, la investigación y la gestión de programas de formación de posgrado en las más importantes instituciones de educación de nivel superior de su país de origen. Tal proceso está mucho más consolidado entre las mujeres de las primeras cohortes, y entre las de las cohortes más recientes se advierte un patrón equivalente. La experiencia migratoria, los estudios de posgrado realizados y el proceso vivido fuera del país, les ha permitido consolidar su proyección profesional y adquirir los conocimientos, habilidades y

${ }^{15}$ Entrevista a Betty, julio de 2010, Colombia. 
recursos para reincorporarse laboralmente en Colombia en mejores términos y con muchas más oportunidades, en contraste con las que tenían antes de la migración internacional.

En el subgrupo de mujeres cuyas edades son más avanzadas se advierte con mayor claridad el condicionamiento del ámbito reproductivo a las exigencias de la trayectoria educativa y laboral. Ninguna tuvo hijos/as durante el extenso proceso formativo, que en la mayoría de los casos culminó al alcanzar el nivel de posdoctorado. La mayoría ha agotado la etapa de la vida reproductiva sin hijos/as. Betty, de la cohorte más joven, es la única que al final de esta etapa asume la maternidad; habiendo iniciado su formación de posgrado en edad más temprana culmina su formación posdoctoral, posteriormente estabiliza una relación de pareja y asume la maternidad. Esta secuencia de los eventos educativos, laborales y reproductivos en la trayectoria de vida de las mujeres migrantes muestra esta articulación de condicionamientos como factores importantes en el dispositivo de la estrategia de movilidad y cualificación.

\section{Distinción con inestabilidad: la incertidumbre del corto plazo}

El grupo de mujeres profesionales en el campo de las ciencias sociales que ha retornado a Colombia se encuentra en esta categoría. Sus trayectorias laborales se caracterizan por un prolongado periodo de vínculos laborales -entre 4 y 12 años- antes de la movilidad internacional y un periodo relativamente corto de formación de posgrado en el exterior -entre 3 y 6 años-, excepto Mary, que permaneció en México por 12 años. La mayoría parte con un título de maestría obtenido en Colombia a realizar sólo estudios de doctorado en el exterior. Sus edades oscilan entre 34 y 55 años y se ubican tanto en la etapa media como en la avanzada del ciclo de vida (diagrama 4 y cuadro 2 ).

La inserción laboral inicial en este grupo de mujeres se presenta en instituciones educativas como profesoras contratistas u hora cátedra o en programas gubernamentales de intervención social. Se desempeñan en cargos de coordinación, orientación o sistematización del proceso de intervención, más que en actividades de ejecución directa o en el campo de los programas. Sus contratos son por tiempo definido $y$, aunque permanecen en el mismo sitio por varios años y experimentan continuidad, en sus contextos predominan la incertidumbre y la inestabilidad. 
La única excepción a las condiciones de contratación temporal referidas es el caso de Teresa, que fue contratada con un término indefinido en una universidad privada donde desempeñó inicialmente funciones administrativas y de atención a la comunidad educativa; después de algunos años, tras obtener un título de maestría, se desplazó al área académica.

Durante la realización de los estudios en México ellas no tienen vínculos laborales formales y sólo eventualmente realizan alguna actividad remunerada. Excepto Mary, que permaneció en México durante 12 años y tras terminar la formación escolar se vinculó como docente por hora cátedra. Posteriormente, de manera simultánea, se desempeñó como coordinadora de un posgrado en una pequeña institución de educación y participó en varias consultorías para organismos de cooperación internacional. Ninguno de estos trabajos constituyó un empleo fijo o estable; todos fueron por contrato temporal.

El grupo de mujeres retornó a Colombia con una posibilidad de vinculación laboral en ciernes; tales ofertas se concretaron en condiciones laborales mucho menos favorables frente a las expectativas generadas o a las promesas iniciales. En todos los casos la reincorporación laboral ocurrió mediante un contrato temporal, casi siempre con una universidad, para desempeñarse como docente/investigadora en la modalidad de contrato anual -que en realidad es de 10 meses- con renuncia "obligada" a fin de año (el 30 de noviembre) y nueva contratación al principio del siguiente año (febrero) si la evaluación de desempeño es favorable. Dichas condiciones de contratación temporal se mantienen al pasar de los años, y ésta es la situación más frecuente en este grupo de mujeres. La excepción es Teresa, quien ya tenía un contrato de término indefinido antes de migrar. En el caso de Dalia, el cambiar de empleo le permitió "negociar" condiciones laborales más favorables, pasando a ocupar un cargo administrativo en otra universidad y con un contrato de término indefinido tras cinco años de retornar a Colombia.

Por tanto las mujeres que migraron por razones de estudio y están adscritas al campo de las ciencias sociales, al retornar se encuentran en medio de un continuum de empleos temporales cuyo horizonte ha permanecido en el corto plazo y se mantienen en una constante incertidumbre laboral. Para este grupo de mujeres las condiciones de contratación no varían de manera significativa en el tiempo. El antes y el después de la migración no cambia sustancialmente en este aspecto, sin embargo se manifiestan otros cambios más sutiles pero importantes y conviene mencionarlos. 
Antes de la movilidad internacional, la mayoría de este grupo de mujeres trabajaba de manera simultánea en dos universidades como profesora por hora cátedra o en tiempos parciales en ambas. Tal situación representa una sobrecarga de trabajo, al tiempo que implica una fragmentación institucional, con múltiples compromisos en una y otra institución, y con muy pocas opciones reales de realizar investigación. La principal variación objetiva en cuanto a las condiciones de trabajo al retorno es la asignación de un tiempo completo en una universidad, la centralidad en un área de especialización y la oportunidad de participar en un grupo de investigación con niveles de liderazgo. El retorno a Colombia con un título de doctorado representa un estatus de distinción que posibilita algunas condiciones más oportunas para la realización del trabajo académico, como las que hemos expuesto. No obstante, está lejos de constituir una garantía de estabilidad laboral y más bien es un lugar de distinción y de privilegio que se alcanza bajo mucha presión y altos niveles de exigencia. El testimonio de Ana ilustra algunos aspectos señalados:

Aquí estoy como profesora asistente, que es la segunda categoría. Es mucho trabajo, pero me gusta mucho. Doy clase en pregrado y en la maestría. Tenemos contrato como pues no sé si indefinido, cada dos años nos hacen como una evaluación para renovárnoslo, pero sí, las condiciones no son buenas, digamos, el salario no es tan bueno yo creo, estoy casi segura que yo ahora me gano lo mismo que me ganaba cuando me fui. La diferencia es que aquí tengo vacaciones remuneradas, y tengo prestaciones y no tengo que pagar de mi sueldo la salud y tengo como que otras condiciones distintas, mayor autonomía en el manejo de mi tiempo, acá tengo un manejo de mi tiempo pues como más libre aunque, en todo caso, es demasiado trabajo. ${ }^{16}$

En este grupo de mujeres se presentan aspectos que son comunes en otros ámbitos de vida y que resulta interesante mencionar. La mayoría ha sostenido relaciones afectivas relativamente duraderas en el tiempo y ha establecido un hogar propio y de convivencia con su pareja. Es más frecuente que hayan tenido hijos/as antes de movilizarse a realizar sus estudios de posgrado en el extranjero. Cuando migraron a México lo hicieron con sus hijos/as y sin su pareja afectiva. En el caso de Zulia, la más joven de este subgrupo, asumió la maternidad a su retorno a Colombia, tras estabilizar una relación afectiva (diagrama 4).

${ }^{16}$ Entrevista a Ana, mayo de 2010, Colombia. 
Entre ellas son evidentes las dificultades y los límites que establece para el proyecto migratorio el tener hijos/hijas y/o sostener una relación afectiva. Por un lado, para su retorno consideran la importancia de ofrecer a sus hijos/hijas la posibilidad de estar más cerca de sus familias de origen y/o de su padre, así como la opción de estabilizar su relación de pareja en Colombia. Por otro lado, esto representa una presión para acelerar la vinculación laboral remunerada aunque se presenten condiciones desventajosas para el nivel de calificación alcanzado y las expectativas que se proyectan.

\section{La movilidad internacional por razones de estudio en las trayectorias laborales de las profesionales}

En los cuatro tipos de trayectorias laborales considerados se ha tomado como eje analítico la estrategia de la movilidad internacional para contrastar la experiencia laboral antes y después de este evento en la trayectoria de las profesionales colombianas. Se han señalado las implicaciones de este proceso comparando a las migrantes de dos ámbitos de conocimiento -ciencias sociales y ciencias naturales-, y a las que optan por permanecer en el país de recepción con las que retornan al país de origen. La configuración de este escenario analítico ha permitido establecer algunos patrones en común y otros de diferencia entre los tipos de trayectoria.

En los cuatro tipos de trayectoria la movilidad internacional por razones de estudio se realiza como un requisito imprescindible para competir por un "lugar" en el mercado de trabajo que provea condiciones laborales favorables para el desempeño profesional, en función de consolidarse como académicas o investigadoras en áreas de especialización en los ámbitos de conocimiento considerados. En tal sentido, esta movilidad puede considerarse un rito de paso, tal como lo expresan explícitamente las mujeres de ciencias naturales que permanecen en México, quienes consideran que otorga credenciales necesarias para aspirar a un mejor empleo, tanto en el país de origen como en el de destino. No obstante, entre los dos campos, ciencias naturales y ciencias sociales, este proceso se vive de manera diferente.

En el campo de las ciencias naturales la movilidad internacional por razones de estudio implica en la mayoría de los casos un decenio continuo dedicado a la formación para alcanzar el rango de experiencia y las credenciales que dan la posibilidad de competir por ese lugar 
anhelado. En este proceso se asume el posdoctorado como una estrategia laboral que marca la diferencia y otorga la oportunidad de dar un giro en sus trayectorias laborales. La movilidad hacia México abre la posibilidad de vincularse con redes académicas y, con ellas, una mayor probabilidad de ingresar a un posdoctorado en un país del primer mundo, lo que está asociado con la inserción en las redes globales del conocimiento y la información y representa un importante y positivo reposicionamiento en el campo académico.

La permanencia en México de este subgrupo de mujeres migrantes está en relación con el logro de condiciones para cumplir con esta meta de empleabilidad. Entre tanto, asumen la formación y la investigación en el laboratorio conforme a las normas usuales de un trabajo por el cual se percibe un ingreso suficiente para vivir. Así, este largo periodo de formación implica una década de austeridad y de bajos ingresos, en condición de becarias. La corta trayectoria laboral desarrollada antes de la movilidad se retoma en una edad avanzada, por ejemplo 40 años en el caso de Elena y 39 en el de Lucía, aún bajo la figura de un vínculo posdoctoral. De tal forma, esta trayectoria redefine su ciclo de vida en aspectos centrales, limita sus posibilidades de acumular un patrimonio material y no considera algún tipo de seguridad social como soporte de ingreso a la edad avanzada. Así mismo, condiciona la vida afectiva, las relaciones de pareja y el ámbito reproductivo en función de las exigencias de las trayectorias educativas y laborales.

El retorno a Colombia de las profesionales en ciencias naturales es una opción válida para una trayectoria laboral "suspendida" por el periodo de formación, pero que conserva alguna certeza o seguridad en el vínculo laboral -licencia en el trabajo, comisión de estudio o fuertes redes en el espacio laboral- que anima el retorno. En estos casos, la movilidad por razones de estudio a México se hace por un periodo más corto y con menor presión en función de la empleabilidad. Para quienes no tienen un vínculo laboral, como Betty, el retorno se afianza con la realización de un posdoctorado en Estados Unidos y la consecución de apoyos financieros para favorecer el retorno al país de origen. Para este subgrupo la movilidad internacional por razones de estudio fortaleció de manera significativa su lugar en el ámbito laboral, y en la actualidad sus integrantes ocupan cargos de dirección en programas académicos pioneros en el país. En estos casos resulta válida la afirmación de que su retorno muestra el éxito del proyecto migratorio que emprendieron y, en este sentido, se le puede caracterizar como un verdadero turning point. Aunque en este subgrupo también aparece 
el condicionamiento de la vida en pareja y el ámbito reproductivo en función de las demandas de la trayectoria educativa y laboral, las mujeres de las cohortes más recientes han ajustado la secuencia de los eventos al iniciar a más temprana edad los procesos formativos y hacerlos sin interrupción en el tiempo, lo cual favorece la posibilidad de asumir la maternidad en los límites de la etapa fértil. La dinámica de estos eventos marcadores de la trayectoria educativa, laboral y reproductiva en este grupo de mujeres está redefiniendo, en la práctica, las transiciones importantes en el curso de vida.

Para las estudiosas de las ciencias sociales que permanecen en México la movilidad internacional ocurre tras una corta experiencia laboral. El paso por las instituciones educativas mexicanas constituye una estrategia de competencia para el mercado laboral y un aval de equivalencia educativa que habilita la inserción en un empleo calificado en la sociedad de destino. La rápida inserción laboral, en la mayoría de los casos, aparece como una alternativa para la incorporación económica y social de las migrantes calificadas, quienes pasan del estatus de estudiantes a la categoría de población económicamente activa, calificada y legal en la sociedad de destino. Esta inserción laboral corresponde con el nivel de calificación que han alcanzado, y su desempeño profesional es relativamente satisfactorio para ellas, a pesar de que predominan los empleos temporales y de relativos bajos salarios. En este subgrupo de mujeres se percibe un amplio universo de oportunidades educativas y laborales en México, y al mismo tiempo que estas expectativas favorecen la permanencia en ese país, también supeditan las decisiones de tipo afectivo y reproductivo, lo que se expresa en una situación de indefinición en estos ámbitos.

A las mujeres de ciencias sociales que retornan a Colombia, la formación de posgrado en México les facilita un reconocimiento en los ámbitos laborales como académicas e investigadoras, sin embargo siguen predominando en su vida laboral las condiciones de empleo temporal, subempleo e intensificación del trabajo. En la mayoría de los casos, a pesar de sus credenciales de alto nivel educativo, viven una fuerte y permanente presión para lograr sostener el vínculo laboral al que han accedido al retornar al país. En este último subgrupo de mujeres se hace más explícita la presión que ejercen los hijos/as y las relaciones de pareja para definir no sólo el retorno al país sino la vinculación laboral en condiciones menos favorables.

En el análisis de los tipos de trayectorias laborales que hemos realizado se advierte que la mayoría de estas profesionales se insertó 
en el mercado laboral en condiciones de flexibilidad, de incertidumbre y de inseguridad social. Tal condición de empleo temporal y de subempleo generalizado se establece como un rasgo predominante en estas trayectorias laborales, tanto en la etapa previa a la movilidad como en la posterior al proceso de cualificación vía la formación de posgrado realizado en México; esta situación se manifiesta con mayor intensidad entre las profesionales de las ciencias sociales, en contraste con las de ciencias naturales.

En este contexto de insuficiencia de empleo y de deterioro de las condiciones laborales en el mercado profesional, cobra pleno sentido nuestro planteamiento en torno a que la movilidad internacional por razones de estudio constituye una estrategia de cualificación por la que opta la población con estudios superiores para enfrentar las nuevas condiciones laborales. Es importante subrayar que las condiciones desventajosas de empleo aparecen tanto en la sociedad de origen como en la de destino, así como en las etapas previa y posterior a la migración, lo que muestra un rasgo estructural del mercado laboral profesional y altamente calificado en las sociedades contemporáneas. De igual forma, esta caracterización introduce la discusión acerca del desperdicio de talentos, tanto en las sociedades de origen como en las sociedades de destino, y acerca de las condiciones laborales desfavorables como una característica general del mercado de trabajo de la población altamente calificada en las sociedades contemporáneas.

La permanencia en México y/o el retorno a Colombia están condicionados por la trayectoria laboral y la configuración familiar; las opciones de quedarse o regresarse expresan diversas estrategias según las percepciones que se tienen del lugar que se ocupa en una estructura de oportunidades dada, que contraste el aquí y el allá. Trayectorias laborales revelan las diversas estrategias de resistencia, de permanencia y de retorno que asumen las mujeres profesionales de las dos áreas de conocimiento para enfrentar los mercados de trabajo, tanto en México como en Colombia.

Por otro lado, es importante subrayar dos cambios sustanciales en la forma en que se presenta la movilidad por razones de estudio en la actualidad: el primero es que ocurre a una edad más temprana y de manera más continua tras la titulación de licenciatura; esto incide significativamente en el calendario de eventos del ciclo de vida productiva y reproductiva de este grupo de mujeres y redefine algunos aspectos centrales del mismo. El segundo es que se presenta cada vez más como una acción que gestionan las mujeres profesionales de ma- 
nera individual, contando básicamente con el acompañamiento y el soporte de sus familias de origen, sin apoyos o vínculos institucionales en la sociedad de origen y sin estar articuladas a un proyecto laboral estable. Todo lo contrario: se da en medio de un deterioro generalizado de las condiciones laborales de este grupo poblacional. La movilidad internacional constituye así una acción que depende en mayor medida de condiciones personales y familiares, y de condiciones favorables de inserción y de financiamiento educativo que se ofrecen a los estudiantes extranjeros para realizar estudios de posgrado en la sociedad de destino.

Para las mujeres de las cohortes más recientes han disminuido los años que transcurren entre la titulación como profesionales y la movilidad internacional, lo que nos lleva a afirmar que esta movilidad es cada vez más necesaria y se vive como una presión más sentida en la actualidad. De esta forma se configuran trayectorias laborales que dan un nuevo lugar a los estudios de posgrado en la vida de los sujetos y a la movilidad internacional como estrategia para obtener estas credenciales académicas.

En la trayectoria de vida de este grupo de mujeres pudimos constatar que la proyección profesional de "hacerse" investigadoras y de ingresar al mundo académico se expresa de manera temprana en sus vidas, no sólo como vocación sino como realización, y que desde entonces definen el proyecto académico como su plan de vida. La presión del medio académico para adquirir los requisitos necesarios para ingresar en él plantea que la movilidad internacional por razones de estudio es un peldaño obligado en este camino. Podemos sugerir que con esta tendencia se expresa -y al mismo tiempo contiene- un cambio que ha ocurrido en el campo académico, en la estructura y en la lógica del mercado laboral específicamente. ${ }^{17}$

${ }^{17}$ Atendiendo al sentido de campo en términos de Pierre Bourdieu, como "una red o configuración de relaciones objetivas entre posiciones. Estas posiciones se definen objetivamente en su existencia y en las determinaciones que imponen a sus ocupantes, ya sean agentes o instituciones, por su situación (situ) actual o potencial en la estructura de la distribución de las diferentes especies de poder (o de capital) -cuya posesión implica el acceso a las ganancias específicas que están en juego dentro del campo-y, de paso, por sus relaciones objetivas con las demás posiciones" (Bourdieu y Wacquant, 1995: 64). 


\section{Consideraciones finales}

Este análisis de las trayectorias laborales de las migrantes profesionales por razones de estudio revela aspectos importantes con respecto al debate contemporáneo sobre el lugar que ocupa el trabajo en la estructuración de la vida de los sujetos y sobre los significados que adquiere la experiencia laboral y, en este contexto, sobre el lugar que ocupa la migración internacional por razones de estudio en la trayectoria laboral y de vida de estas profesionales colombianas.

En este grupo de mujeres se encuentran trayectorias laborales y de vida que se han configurado bajo la lógica de garantizar situarse y alcanzar la mejor posición en el campo académico y de investigación como lugar deseado, en la medida en que otorga un lugar de distinción en la posesión de capital escolar y de prestigio por el tipo de reconocimiento social que lo acompaña.

En la configuración de estas trayectorias los primeros vínculos laborales abren puertas que favorecen la inserción de estas profesionales en ámbitos y espacios de su interés -a pesar de las condiciones laborales de desventaja- y que les otorgan el respaldo institucional necesario para acceder al camino deseado. Para algunas mujeres fue necesario desempeñar actividades de carácter voluntario para mantener el espacio y los contactos y acreditar la experiencia necesaria en su proyección profesional y laboral de mediano plazo.

En este camino, la movilidad internacional por razones de estudio adquiere un carácter cada vez más imprescindible en las cohortes recientes para desarrollar una carrera laboral en el campo académico. Ha de llevarse a cabo de manera inmediata tras obtener la titulación profesional, como requisito indispensable para posicionarse en el mercado laboral profesional académico, como experiencia de vida, y como credencial para lograr el reconocimiento necesario que permita competir, en mejores condiciones, en el mercado laboral profesional académico, tanto en el país de origen como en el país receptor. Esta aspiración que dinamiza la movilidad internacional presenta resultados diversos en su eficacia simbólica, dependiendo de diversos factores.

En los cuatro tipos de trayectorias que analizamos se presentan escenarios diferenciados entre áreas de conocimiento, que se cruzan con las condiciones del país de origen y el de destino. En estos escenarios las mujeres, con diversos capitales escolares y sociales, ponen en marcha procesos de permanencia o de retorno en función de las 
expectativas laborales y educativas, así como de crecimiento y de prestigio profesional que se ponen en juego.

La reconstrucción de estas trayectorias nos permitió identificar una importante variabilidad en los cursos de vida de este grupo de mujeres, quienes a pesar de pertenecer a un mismo subgrupo profesional o categoría de análisis, presentan trayectorias heterogéneas. El alcance de la migración como punto de quiebre, la movilidad por razones de estudio, aparece en algunas mujeres como un momento de transición, y en otras constituye un verdadero turning point. Tanto en unas trayectorias como en otras se expresan formas distintas de asumir el trabajo profesional en las sociedades contemporáneas y se evidencia la variedad de estrategias a las que se acude en función de conservar o alcanzar un lugar en el mundo del trabajo y lograr el desempeño profesional académico proyectado.

Conviene subrayar que ésta es una primera aproximación al estudio de las trayectorias laborales de mujeres migrantes calificadas en flujos sur-sur, no hegemónicos, que han sido muy escasamente analizadas, de ahí que el presente esfuerzo deje abierta una línea de investigación que requiere el desarrollo de investigaciones comparativas que permitan profundizar lo aquí sugerido. En tal sentido, es necesario identificar las singularidades de los flujos sur-sur con respecto a los flujos sur-norte para establecer con precisión los factores generales y específicos que cobran importancia para comprender las lógicas que subyacen en cada caso y los procesos sociales de orden más general que estas dinámicas migratorias permiten visualizar. En particular, es necesario profundizar en el tipo de conexiones de estos renovados flujos de migración calificada con los procesos de reconfiguración social en los países de la región, en función de precisar cuáles son las articulaciones de las dinámicas del cambio en la estratificación social con el fenómeno de la migración calificada en el contexto de la globalización y de la implementación de los recientes modelos de acumulación.

\section{Bibliografía}

Arriagada, Irma (2002), "Cambios y desigualdades en las familias latinoamericanas”, Revista de la CEPAL, núm. 77, pp. 143-161.

Bermúdez, Rosa Emilia (2007), Mujeres obreras e identidades sociales. Cali, 19301960, Medellín, La Carreta Editores / Universidad ICESI. 
Bermúdez, Rosa Emilia (2012), "Migración internacional calificada por razones de estudio: colombianas en México”, tesis de doctorado en Estudios de Población, México, El Colegio de México.

Blanco, Mercedes (2001), "Trayectorias laborales y cambio generacional: mujeres de sectores medios en la Ciudad de México", Revista Mexicana de Sociología, vol. 65, núm. 2, pp. 91-111.

Blanco, Mercedes (2011), "El enfoque del curso de vida: orígenes y desarrollo", Revista Latinoamericana de Población, año 5, núm. 8, pp. 5-31.

Blanco, Mercedes y Edith Pacheco (2003), "Trabajo y familia desde el enfoque del curso de vida: dos subcohortes de mujeres mexicanas", Papeles de Población, vol. 9, núm. 38, pp. 159-193.

Bourdieu, Pierre y Loic Wacquant (1995), Respuestas. Por una antropología reflexiva, México, Grijalbo.

Docquier, Frédéric, B. Lindsay Lowell y Abdeslam Marfouk (2009), “A Gendered Assessment of Highly Skilled Emigration”, Population and Development Review, vol. 35, núm. 2, pp. 297-321.

DANE (2005), Censo Nacional de Vivienda y Población de Colombia, Bogotá, Departamento Administrativo Nacional de Estadística.

De la Garza, Enrique (2007), "Los estudios laborales en América Latina a inicios del siglo XxI”, Sociología del Trabajo, núm. 61, pp. 3-24.

De la Garza, Enrique (2011), "Trabajo a-típico, ¿identidad o fragmentación?: alternativas de análisis”, en Edith Pacheco, Enrique de la Garza y Luis Reygadas (coords.), Trabajos atípicos y precarización del empleo, México, El Colegio de México, pp. 49-80.

De la O, María Eugenia (2001), “Trayectorias laborales en obreros de la industria maquiladora en la frontera norte de México: un recuento para los años noventa”, Revista Mexicana de Sociología, vol. 63, núm. 2, pp. 27-62.

Elder, Glen (2001), "Life Course: Sociological Aspects", en Neil Smelser y Paul Baltes (coords.), International Encyclopedia of the Social and Behavioral Sciences, vol. 13, Oxford, Elsevier.

Elder, Glen y Mónica Kirkpatrick (2000), "The Life Course and Aging: Challenges, Lessons, and New Directions”, Chapel Hill, University of North Carolina. Disponible en: <http://www.ccsr.ac.uk/research/iplc/Elder. pdf $>$.

Fitoussi, Jean Paul y Pierre Rosanvallon (1997), La nueva era de las desigualdades, Buenos Aires, Manantial.

García, Brígida (2011), "Carencias laborales en México: conceptos e indicadores”, en Edith Pacheco, Enrique de la Garza y Luis Reygadas (coords.), Trabajos atípicos y precarización del empleo, México, El Colegio de México, pp. 81-113.

García, Brígida, Mercedes Blanco y Edith Pacheco (2000), "Género y trabajo extradoméstico", en Brígida García (coord.), Mujer, género y población en México, México, El Colegio de México / Sociedad Mexicana de Demografía, pp. 273-304. 
García, Brígida y Orlandina de Oliveira (1998), Trabajo femenino y vida familiar en México, México, El Colegio de México.

Guadarrama, Rocío (2008), "Los significados del trabajo femenino en el mundo global. Propuesta para un debate desde el campo de la cultura y las identidades laborales”, Estudios Sociológicos, vol. 26, núm. 77, pp. 321-342.

Hualde, Alfredo (2001), "Trayectorias profesionales femeninas en mercados de trabajo masculinos: las ingenieras en la industria maquiladora", Revista Mexicana de Sociología, vol. 63, núm. 2, pp. 63-90.

Jiménez, Mariela Sonia (2009), "Tendencias y hallazgos en los estudios de trayectoria: una opción metodológica para clasificar el desarrollo laboral", Revista Electrónica de Investigación Educativa, vol. 11, núm. 1, <http:/ / redie. uabc.mx/vol10no2/contenido-jimenez.html> (29 de marzo de 2010).

Lozano, Fernando y Luciana Gandini (2011), "Migración calificada y desarrollo humano en América Latina”, Revista Mexicana de Sociología, núm. 4, pp. 675-713.

Pacheco, Edith y Mercedes Blanco (2005), "Análisis del efecto edad-periodocohorte en el nivel de participación económica de tres cohortes de mujeres mexicanas", Papeles de Población, vol. 11, núm. 43, pp. 79-103.

Pacheco, Edith y Mercedes Blanco (2008), "Work and Family: An Exercise in Mixed Methodology”, Forum: Qualitative social research Sozialfors, vol. 9, núm. 1, art. 28.

Parela, Sonia y Leonardo Cavalcanti (2010), "La movilidad ocupacional de las mujeres inmigrantes brasileñas en España”, Economía y Sociedad, núm. 19, pp. 11-32.

Pérez Sainz, Juan Pablo y Minor Mora Salas (2004), "De la oportunidad del empleo formal al riesgo de exclusión laboral. Desigualdades estructurales y dinámicas en los mercados latinoamericanos de trabajo", Alteridades, vol. 14, núm. 28, pp. 37-49.

Prieto, Carlos (2008), "Trabajo y orden social: de la nada a la sociedad de empleo (y su crisis)”, en Carmen Marina López Pino et al. (coords.), Vías y escenarios de la transformación laboral: aproximaciones teóricas y nuevos problemas, Bogotá, Universidad del Rosario, pp. 53-78.

Sennett, Richard (2000), La corrosión del carácter. Las consecuencias personales del trabajo en el nuevo capitalismo, Barcelona, Anagrama.

Solís, Patricio (2011), "Desigualdad y movilidad social en la Ciudad de México", Estudios Sociológicos, vol. 29, núm. 85, pp. 283-298.

Suárez, Leticia (1992), "Trayectorias laborales y reproductivas: una comparación entre México y España”, Estudios Demográficos y Urbanos, vol. 7, núms. 2 y 3 (20-21), pp. 359-375.

Tilly, Charles (1998), La desigualdad persistente, Buenos Aires, Manantial.

UNESCO (2004), Compendio mundial de la educación 2004: comparación de las estadisticas de educación en el mundo, Montreal, UNESCO.

UNESCO (2007), Compendio mundial de la educación 2007: comparación de las estadísticas de educación en el mundo, Montreal, UNESCO. 
Bermúdez Rico, TRAYECTORIAS LABORALES DE MIGRANTES

UNESCO (2012), Global Education Digest 2012. Opportunities Lost: The Impact of Grade Repetition and Early School Leaving, Montreal, UNESCO.

Urrea, Fernando (1999), "Globalización, subcontratación y desregulación laboral”, en Fernando Urrea et al., Innovación y cultura de las organizaciones en tres regiones de Colombia, Bogotá, Colciencias / Corporación Calidad, pp. 219-281.

Villasmil, Mary Carmen (1998), "Apuntes teóricos para la discusión sobre el concepto de estrategias en el marco de los estudios de población”, Estudios Sociológicos, vol. 14, núm. 46, pp. 69-88.

Welti, Carlos y Beatriz Rodríguez (2000), “Trabajo extradoméstico femenino y comportamiento reproductivo”, en Brígida García (coord.), Mujer, género y población en México, México, El Colegio de México / Sociedad Mexicana de Demografía, pp. 317-354.

Zamora, Eliana Andrea (2009), "Conquistando el sueño americano: trayectorias laborales de éxito profesional”, Economía y Sociedad, núm. 17, pp. 115139.

Zapata, Francisco (1998), ¿Flexibles y productivos?: estudio sobre flexibilidad laboral en México, México, Centro de Estudios Sociológicos, El Colegio de México.

\section{Acerca de la autora}

Rosa Emilia Bermúdez Rico es doctora en Estudios de Población por El Colegio de México y maestra en Sociología por la Universidad del Valle (Cali, Colombia). Actualmente es profesora investigadora en el Departamento de Ciencias Sociales de la Universidad del Valle e integrante del grupo de investigación "Estudios étnico-raciales y del trabajo en sus diferentes componentes sociales" en dicha universidad.

Algunas de sus publicaciones son: Inserción laboral de jóvenes profesionales (en coautoría con Johnny Orejuela, Carmen Urrea y Angélica Delgado), Bogotá, Bonaventuriana, 2013; "Migración calificada e integración en las sociedades de destino”, Sociedad y Economía, núm. 19, pp. 135-150, 2010; Poblaciones y territorios en disputa, Cali, Universidad ICESI, 2009; Trabajo, identidad y carácter. Dilemas y conflictos de la reestructuración laboral (en coautoría con Felipe Van der Huck y Antonio Fernández), Cali, Universidad ICESI, 2010; Mujeres obreras y construcción de identidades sociales, Cali 1930-1960, Medellín, ICESI / La Carreta, 2007. 
